Rhode Island College

Digital Commons @ RIC

\title{
Nurses Perceptions' of Bedside Reporting on an Intensive Care Unit Following Implementation
}

Christine McGinn

Rhode Island College

Follow this and additional works at: https://digitalcommons.ric.edu/etd

Part of the Critical Care Nursing Commons

\section{Recommended Citation}

McGinn, Christine, "Nurses Perceptions' of Bedside Reporting on an Intensive Care Unit Following Implementation" (2017). Master's Theses, Dissertations, Graduate Research and Major Papers Overview. 180.

https://digitalcommons.ric.edu/etd/180

This Thesis is brought to you for free and open access by the Master's Theses, Dissertations, Graduate Research and Major Papers at Digital Commons @ RIC. It has been accepted for inclusion in Master's Theses, Dissertations, Graduate Research and Major Papers Overview by an authorized administrator of Digital Commons @ RIC. For more information, please contact digitalcommons@ric.edu. 

Nurses Perceptions' of Bedside Reporting on an Intensive Care Unit Following Implementation

A Major Paper Presented

by

Christine McGinn

Approved:

Committee Chairperson

Committee Members

(Date)

(Date)

(Date)

Director of Master's Program

(Date)

Dean, School of Nursing

(Date) 
Nurses Perceptions' of Bedside Reporting on an Intensive Care Unit Following Implementation

by

\title{
Christine McGinn
}

\author{
A Major Paper Submitted in Partial Fulfillment \\ of the Requirements for the Degree of \\ Master of Science in Nursing \\ in
}

The School of Nursing

Rhode Island College

2017 


\begin{abstract}
Shift handoffs were included in The Joint Commission's 2009 National Patient Safety Goals, which requires that shift hand-offs must include up-to-date information about the care, treatment, current condition, and recent or anticipated changes with the patient. Bedside reporting addresses The Joint Commission's Goal 13, a safety strategy that encourages the patient's active involvement in care. The demand for quality care while caring for the sick population with multisystem complex diagnoses calls healthcare provides to look at ways to provide more efficient care while improving patient safety and outcomes.
\end{abstract}

Bedside reporting is one nursing intervention which can be implemented to improve communication, increase patient safety and improve the quality of care. While on the surface the benefits of bedside reporting seem clear, some who have tried to implement bedside shift reports have faced significant challenges. This quality project surveyed 32 nurses on a trauma unit to determine their perceptions of bedside reporting following implementation over 2 years ago. Nurses were provided with a ten question survey based on a Likert scale of 1-5. One additional qualitative question asked nurses 'perceptions and thoughts about the bedside reporting process.

Results overall revealed that although many nurses were aware of the benefits of bedside reporting and its practical uses, most nurses still were hesitant with its daily practice. Despite strong evidence demonstrating the benefits of bedside reporting, many issues still remain regarding the sustainability after implementation. 


\section{Acknowledgements}

Foremost, I would like to express my sincere gratitude to Dr. Carolyn Wood for her continuous support of my research, her patience, motivation, enthusiasm and mostly for keeping me focused and calm in times when this felt impossible. I could not have imagined having a better mentor for this process. Dr. Cynthia Padula who was a tremendous help in overseeing the start of this project, thank you. To Deb Servello, who has always been such a great source of support and knowledge, thank you for always listening. Lastly, I would like to thank three of the greatest classmates I have had the

pleasure of knowing. Susan H, Liz W and Ashley C. I would never have made it through this program without the three of you. We managed to keep each other sane and positive through all this. I am so excited for what the future has in store for us.

When they say it takes a village, they were right. To my amazing mother who always encouraged me to pursue an education, I thank you for doing absolutely everything for me and my family. Even when your hands were full, you dropped everything for us. I have no words that could possibly explain my gratitude to you. To my in laws who have been amazing in helping Mike and I with raising my two girls, I am forever grateful that my kids are surrounded with such love. To my aunt who constantly pushed me to my highest abilities and was a huge support during school from the very start, thank you. To my coworkers and friends, I love you all so much!

To my beautiful girls Raegan and Riley, thank you for keeping me grounded, motivated and teaching me to see life through fresh eyes. Your pictures have been on every single folder of mine; your precious faces were my motivation. And to my husband Mike, you have been unfailingly supportive - and have borne the burdens which have 
fallen into your lap. This year especially has been a long haul and there's so much to thank you for: for doing note cards with me, listening to me non stop at the dinner table, for taking care of the kids and household duties without complaint. I would have NEVER accomplished this without you as my partner. I wish there was room on my diploma to write your name too. Invincible

I dedicate this major paper to my father... I wish you were here every single day. I know you would be so proud. You were always my biggest fan and for that I thank you forever. 


\section{Table of Contents}

Background/Statement of the Problem ............................................................... 1

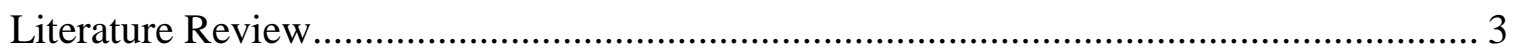

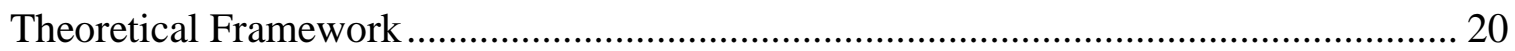

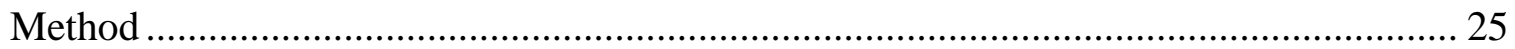

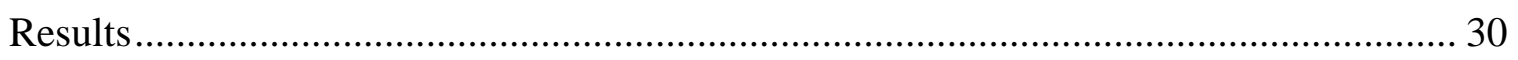

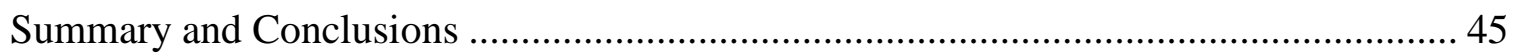

Recommendations and Implications for Advanced Nursing Practice .......................... 48

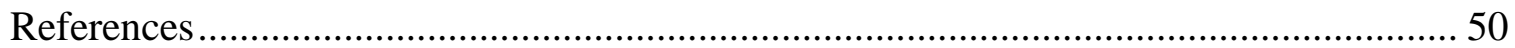

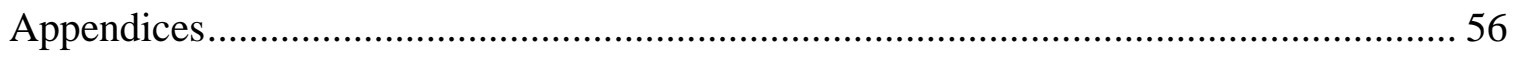




\section{Nurses' Perceptions of Bedside Reporting on an Intensive Care Unit Following Implementation}

\section{Background/Statement of the Problem}

Bedside reporting has been found to increase patient involvement and satisfaction, boost nursing teamwork and accountability, and improve the effectiveness of communication among providers. Instituting bedside report allows nurses to positively impact patient experiences by putting patients at the center of their own care and allows patients to be an active participant in their own recovery. Other benefits include teamwork, accountability of peers and overall increased quality and safety. (Bridges, 2003; Chaboyer, 2010; Evans, 2011; Friesen, 2013).

According to Friesen et al. (2013), bedside report occurs at the point of care and consists of communication about a patient's condition, assessment, plan of care, as well as a general survey of the environment to evaluate safety. Evidence supports bedside report as a mechanism to improve communication, patient safety, quality of report, and nurse and patient satisfaction when implemented correctly (Friesen, 2013). The Joint Commission (TJC) estimated that $65 \%$ of sentinel events were the result of communication problems, especially during change of shift report which prompted the TJC to require a standard way of shift report as a part of the National Patient Safety Goals (Cornell, Townsend-Gervis, Yates \& Vardaman, 2013). Utilizing bedside reporting as a universal protocol is one strategy that in part meets the requirements of these goals. The Agency for Healthcare Research and Quality defines bedside handover as the transfer of information along with authority and responsibility during transitions in care across the continuum; to include an opportunity for hospitals to develop effective partnerships with patients and family members with the ultimate goal of improving multiple aspects of hospital quality and safety. Adopting bedside handover can allow both patients and families to play a role to make sure these transitions in care are safe and effective. 
The purpose of this project is to examine critical care nurses' perceptions of bedside report. The goal is to explore the perceptions of bedside reporting and evaluate nurses' perceptions following the implementation of bedside reporting in the Trauma Intensive Care Unit (TICU).

Next, the Literature review will be discussed. 


\section{Literature Review}

A comprehensive literature search was conducted regarding the use of bedside reporting. The databases PubMed, Ovid, Medline and CINAHL were searched. The following keywords and combination of these were used for the search: nursing report, bedside reporting, patient safety, quality care, patient-centered care, benefits and barriers to bedside reporting. These key word topics produced an array of articles that were evaluated and articles were chosen based on relevance to the topic. Articles searched and reviewed were published between the year 2000 and 2015 . The limitations of the search were all articles written in English.

\section{Nursing Report}

Although performed on a daily basis, shift report has been a topic of debate and has been found to be an inconsistent element of nursing practice. There are many different forms of nursing report. Some units do report in a back room, some use a tape recorder, some take verbal report after reading the SBAR. Welsh, Flanagan, and Ebright (2010) conducted a qualitative, descriptive study to illustrate handoff procedures for nurses at change-of-shift using two types of handoff, taped and written. A convenience sample of 20 nurses from three inpatient units of a Midwestern veteran's administration medical center participated in structured interviews. Of the 20 nurses included, 7 nurses were from the day shift, 9 nurses from the evening shift, and 4 nurses from the night shift. Data analysis consisted of a theory approach in which two investigators coded the data into "barriers," "facilitators," and "other" categories (p. 149). Themes were then analyzed using a nursing expert in that field. Barriers that were identified included: incomplete report, incomplete information, differences between nurses, equipment malfunction, and 
interruptions. Facilitators included: ability to ask questions freely, able to take report while listening, and more pertinent information relayed to the oncoming nurse.

Authors Pothier, Monteiro, Mooktiar, \& Shaw (2005) compared three different styles of nursing report to determine the amount of information lost for each style. The researchers created a simulated hand off experience using twelve fictional patients and gave report five consecutive times between nurses. The sample was a convenience sample of 5 nurses. The patients were randomly assigned to three groups representing the three different styles of hand off: verbal report, written report, and pre- printed sheets and/or note taking report. Each nurse had the opportunity to participate in each of these different style reporting. The three handover styles were used and the amount of data lost was recorded for each style. A strictly verbal handover style resulted in the loss of all data after three cycles. A note-taking style (the traditional style used in most hospitals) resulted in only $31 \%$ of data being transferred correctly after five cycles. When a typed sheet was included with the verbal handover, data loss was minimal. The differences between the three groups were statistically different $(p<0.001)$. A strong point of this study was that the researchers made an attempt to randomize the data collection and had control over the type of patient secondary to simulation. The simulation provided consistency in patient information. The major weakness of the study was the very small sample size of 5. Anderson and Mangino (2006) add that these so called traditional methods of shift report allow for little communication between nurses, and in the end can have a negative impact on patient safety related to incomplete information being relayed. 


\section{Traditional Versus Non Traditional Nursing Report}

Various methods of shift report have been used over the years, from verbal report outside the patient room, to report in a conference room, to a combination of taped and verbal report (Caruso, 2007). Regardless of the report method, the literature is consistent regarding the problems associated with change-of-shift report. The problems include a lack of report consistency and structure, potential failures in communication leading to adverse events, and not allowing the patient to be included in their plan of care (Cairns, Dudjak, Hoffmann, \& Lorenz, 2013; Friesen et al, 2013; Jeffs et al, 2014). Much of the literature has found that many medical errors involve actual inaccuracies with communication. The errors can involve all members of the healthcare team and can be an omission such as failing to communicate laboratory results or medical information to another caregiver, resulting in preventable complications (Agency for Healthcare Research and Quality (AHRQ), 2003. Although miscommunication can occur at any time during a patients' care, the greatest risk has been found to be during shift handover (Sand-Jecklin \& Sherman, 2013).

The Joint Commission (TJC) estimated that $65 \%$ of sentinel events were the result of communication problems, especially during change of shift report. As cited in Cornell, Townsend-Gervis, Yates, \& Vardaman, (2013). Traditionally, report most often occurs in a place removed from the clinical setting and without the patients' knowledge or input (Kerr, Sai Lu \& McKinlay, (2013). Traditional methods of bedside reporting don't allow for patients to be involved in their care or communicate any needs that they may have at that given moment. Maxson, Derby, Wrobleski, and Foss (2012) conveyed that when patients are given the opportunity to participate in bedside report, they are more likely to 
contribute to their care and to be kept informed of their condition thus leading to increased patient satisfaction.

The Agency for Healthcare Research and Quality defines bedside reporting as an opportunity to make sure there is effective communication between both patients and families, and nursing staff and that bedside reporting can create an environment where patients and their families can work together to improve the quality and safety of care. The goal of the AHRQ in regards to nurse bedside shift report is to help ensure the safe handoff of care between nurses by involving both the patient and family. Patient and family engagement creates an environment where patients, families, clinicians, and hospital staff all work together as partners to improve the quality and safety of hospital care. Patient and family engagement encompasses behaviors by patients, family members, clinicians, and hospital staff as well the organizational policies and procedures that support these behaviors. The AHRQ feels as though engaging in bedside reporting can improve patient quality and safety, patient satisfaction in care, nurse staff satisfaction, better communication and accountability between nurses. Many hospitals are now redesigning current shift report practices to meet the standards set forth by The Joint Commission through the national patient safety goals that address communication (Welsh et al., 2010). Griffin (2010) suggested that traditional shift report may be a time for nurses to socialize and share personal information about their own lives. The use of bedside reporting therefore allows the focus to be on the patient, which makes the report more relevant, objective and overall more concise. Therefore, bedside reporting offers options to address the inefficiencies of conventional nursing report.

Patients and family members witness staff communication, professionalism, and 
organization as responsibility is transitioned from one nurse to another during face to face reporting. Patients feel as though they are part of the team and appreciate having input in their care. Welcoming the participation of patients and families offers both the patient and family member the opportunity to participate in the exchange of information (Caruso, 2007). Participating in bedside reporting will help ensure that the staff, patient, and the families all have knowledge of the treatment plan ahead.

\section{Definition of Nursing Bedside Report}

According to Friesen et al. (2013), bedside report occurs at the point of care and consists of communication about a patient's condition, assessment, plan of care, as well as a general survey of the environment to evaluate for safety. Bedside report has been described as the transfer of essential patient information and the responsibility of patient care between nurses coming on shift and nurses completing their shift (Jeff's et al., 2014). Essentially, nursing report is the time when one nurse transfers accountability and responsibility of their patient to another nurse. Report is an important time where details about a patient's condition, treatment, and care planning are communicated. Much of the current literature describes bedside reporting as a way for nurses to report shift changes and to communicate a patients' condition or status in a more thorough and comprehensive manner.

\section{Advantages of Bedside Reporting}

Bedside shift report reassures the patient that the staff works as a team and that everyone knows the plan of care. Patients can ask questions or add information to the discussion. Evidence suggests that patients who are better informed are less anxious and more likely to follow medical advice (Anderson \& Mangino, 2006). Anderson \& Mangino 
used a monthly quantitative patient satisfaction survey in a large 600 bed Arizona hospital to evaluate the implementation of bedside handover. The unit consisted of 32 surgical beds. Both patient and staff satisfaction was measured pre and post implementation of bedside reporting. Numerous outcomes, including financial savings and increased patient satisfaction, increased staff satisfaction and physician satisfaction, were observed on the unit. The researchers also found a decrease in incidental over time by 100 hours in the first two pay periods, followed by an additional decrease in another 100 hours in the following pay period. Staff members also felt as though their priorities changed once they finished getting report since they could visualize the patients' needs right away. An additional benefit was that the physicians felt that the nurses were overall more informed about their patients' and were satisfied with the change. Patient satisfaction scores were tallied in three main areas: how well the nurses kept the patients informed, how well staff worked together as a team and how well staff included the patients' in their treatment plan (Anderson \& Mangino).

Kelly (2005) conducted a qualitative study which surveyed nurses and patients on a 12 bed rehab unit in a rural Irish 142 bed community hospital. Initially, like many other facilities, report was given at the nurse's station or in the back room. A short questionnaire was distributed to patients $(\mathrm{n}=10)$ asking how they perceived nursing report once bedside reporting was underway. The results revealed that eight patients felt more involved in their care (Kelly 2005). The participants in the study were chosen randomly, and the sample size was overall small. Results attested that after changing to bedside report, 11 of the 18 nurses felt they were more informed about the patients' conditions and also felt as though patients were more involved in their own care. 
Chaboyer, McMurray, Johnson, Hardy, Wallis and Chu, 2009 conducted a qualitative study and found that staff conveyed an improved sense of team work which in turn improved overall satisfaction. The survey was conducted after bedside reporting was implemented in three separate units in a 330 bed Australian hospital. Surveys were conducted six months after implementation on two of the three units. The change was received positively by both staff and patients. Staff members reported that bedside handover improved safety, efficiency, teamwork, and the level of support from senior staff members. They also believed bedside reporting kept patients' better informed about their care (Chaboyer et al.). The study cites that nurses felt as though the patients were overall more satisfied when report was done face to face. Nurses also felt that it increased accountability and improved communication with coworkers and patients. Chaboyer et al.), conveyed that patients perceived the change to the bedside positively and conclude that patients had a clearer understanding of the plan of care when handoffs occurred at the bedside.

In a mixed methods study, Sand-Jecklin \& Sherman (2013) used anonymous surveys of both patients and nurses to evaluate the processes and outcomes of moving from a recorded change-of-shift report to bedside report. The study took place in a Medical Surgical Unit in a West Virginia University healthcare center. An adapted Patient Views on Nursing Care instrument was used to survey the patients. The survey was conducted both pre-implementation ( $n=232$ patients) and post implementation ( $n=178$ patients). Sand-Jecklin \& Sherman found significantly higher post implementation patient scores on the following questions: "made sure I knew who my nurse was," "included in shift report discussion," and "communicated important information about care" (p. 190). The Nursing 
Assessment of Shift Report instrument, developed by Sand-Jecklin \& Sherman, was used to survey the nurses using the same pre-post implementation design. Sand- Jecklin \&Sherman reported significant (improvement after implementation) higher nurses scores in several areas including effective and efficient means of communication, ensuring accountability, and promoting patient involvement in care.

In a study of by Jeffs et al. (2014) nurses were interviewed and surveyed in an inner city hospital in Canada after the implementation of bedside reporting on their unit. Jeff, et al used the interview process to explore the experience of nurses following implementation of bedside reporting. Two major themes emerged in their interviews: clarifying information and intercepting errors; and visualizing patients and prioritizing care. The interview was conducted with standardized interview questions. Patients felt as though bedside report provided a chance for personal connection with their caregivers and allowed patients to be more knowledgeable about the plan of care. One negative finding was that the researchers noted varying exposure of patients to the bedside report process; meaning some were there for a short period of time and others there for a much longer hospital stay. (Jeffs et al., 2014).

Another topic that emerged in the literature was the subject of distraction during the traditional nursing report at the nurses' station. In a qualitative survey by Johnson and Cowin (2013), done in Sydney Australia, staff noted that the working environment was less noisy and less disruptive when report took place at the bedside and that fellow staff members overall listened better to report. The aim of the study was to explore nurses' perspectives on the introduction of bedside handover over the use of written report sheets. Using a qualitative approach, data was obtained from six focus groups containing 30 
registered nurses. Thematic analysis revealed several major themes including: bedside handover and the strengths and its weaknesses, patient involvement in handover, and good communication.

Both patients and nurses recognize the benefits of bedside shift report. Maxson et al., (2012) conducted a quantitative study with a convenience sample of 60 patients to determine if bedside report increased patient satisfaction scores and patients' perception of unit teamwork. The researchers also examined if bedside report increased staff satisfaction in regards to communication and accountability; $5 \mathrm{RN}$ nurses were surveyed. The authors revealed statistically significant increases in patient perception of their involvement in the plan of care $(p=0.02)$ and nurses' perceptions regarding accountability for themselves $(p=0.0005)$ and confidence in their medication reconciliation and knowledge $(p=0.0003)$. The sample size of nurses was small however and represented a smaller than average sample size.

\section{Patient Quality and Safety Related to Communication}

Two-thirds of all sentinel events can be linked to poor communication (The Joint Commission, 2013). The Joint Commission has estimated that "80 percent of serious medical errors involve miscommunication between caregivers during a nursing hand-off" (Joint Commission 2015). With increasing scrutiny of patient safety and quality of care, the Joint Commission has put forward a set of patient safety goals to improve the quality of care. The 2015 Hospital National Patient Safety Goal is to improve the effectiveness of communication among caregivers. One way to improve safety between nurses and patients would be the implementation of bedside reporting where patients are more involved in their care while receiving medical treatment. Bedside handoffs allow for a face to face 
interaction that includes the patient, clarification and potential resolution of erroneous information, introduction of the oncoming nurse and an assessment of the patient during the report (Freisen et al, 2008). Bedside reporting allows for visualization of the patient and the environment. In turn, face to face report allows for the current nurse to do a safety check with the oncoming nurse. Each nurse can then visualize the pumps, assess the working environment, check lines, devices etc. In all, health care practitioners have a responsibility to ensure safety and quality when providing care for patients. Verbal report alone, without the patients' collaboration, can impact safety if information is incomplete or communicated poorly because of interruptions or distractions (Anderson \& Mangino, 2006).

In the study previously cited by Chaboyer et al., (2010) results indicated that six months after implementation of bedside reporting, $44 \%$ of the 27 nurses surveyed responded that they believed that face to face shift report improved patient safety and also improved patient outcomes at discharge planning. Reasons stated included: the bedside the nurse can visualize what he or she has done for the patient; Face to face report can reveal patient cues such as facial expressions, especially if a patient is unknown to the oncoming nurse.; the process of bedside reporting has taught nurses to be more accountable, think about what they hand over and why; It can provide a time for peer to peer teaching and accountability, especially if the report is between a seasoned nurse and a novice nurse. Bedside reporting has then become an opportunity for teaching moments (McMurray, Chaboyer, Wallis, \& Fetherston, 2010).

Athwal et al., (2009) documented a decrease in falls after the implementation of bedside handoffs from one to two per month to only one in six months. The unit 
previously conducted verbal report in a conference area away from patients. The unit consisted of 34 beds with 55 employed nurses. Following the implementation of bedside reporting, the researchers found that report time decreased from approximately 40 minutes to 10 minutes, reducing the amount of overtime being paid. They also found that falls decreased from eight in the six-month pre-implementation to one in the six months' post implementation period.

As previously described in a study by Sand-Jecklin \& Sherman 2013, a decrease in the amount of falls was also documented. Falls rates decreased from 20 to 13 , three months' post implementation of bedside reporting and medication errors had decreased by $10 \%$. The findings suggest that bedside reporting can have a huge impact on patient safety and it can also improve the patient experience while in the hospital.

Radtke (2013) conducted a pilot study to improve communication between patients and nurses at the time of discharge. The purpose of this study was to determine if standardizing shift report improves patient satisfaction with nursing communication. A discharge patient survey $(n=280)$ showed the need for enhancement of communication with staff. As a result of the pilot study, management decided to implement bedside handover in a medical/surgical ward to evaluate if it would help improve patient satisfaction. After three months of implementation, 44 patients were interviewed and 20 were surveyed. The survey asked if the nurses communicated well with the patient what was expected after the patient was discharged home and if they felt prepared to go home with proper instructions. The study showed an increase in patients' perceptions of continuity of care and of nurses meeting their individual care needs. This study was strengthened by the adoption of Lewis's Planned Change Theory to guide the process of 
change in their unit.

Evans, Grunawalt, McClish, Wood, \& Friese, 2012, conducted research in a Michigan Hospital in a 32 bed medical -surgical unit that consisted of 42 full time nurses. The goal was to strengthen the patient centered care model. With approved guidelines and with staff input, eight beds were approved for this pilot study. Staff nurses collected baseline data from fellow coworkers prior to implementation of bedside reporting to evaluate change. Nurses were asked to complete a survey about their satisfaction with the nursing report process. Post implementation results showed that nurses were slow to adopt change however as their comfort levels increased they were more accepting of the process. As identified in the post survey questions, three significant issues came about during implementation of the new report process. First, nurses felt as though patients sometimes would interrupt and prolong report. Second, nurses voiced a concern about giving report in a semi-private room which they felt would violate patients' rights. Finally, assignment realignment worked well for the nurses but did however create unintended adverse effect for nursing techs who usually were assigned to more than four rooms and therefore could not be present for bedside report at each point of care. Evans et al. (2012) found that patient safety was improved in regard to bedside report and led to avoidance of adverse patient events. The researchers stated that nurses were able to visualize the patient and noticed if differences from the initial encounter with the patient occurred. The researchers found that nurses verbalized that they were able to assess the environment around the patient, including checking IV lines, and chest tube drainage devices that needed prompt attention. (Evans, Grunawalt, McClish, Wood, \& Friese, 2012, p. 284). 


\section{Patient and Family centered care}

Family centered care is defined as "an innovative approach to planning, delivery and evaluation of healthcare, governed by mutually beneficial partnerships between the health professional, patient and family" (Institute for Patient and Family-Centered Care 2010, p.1). There is a significant focus in the literature on patient family-centered care. This approach to healthcare is based on collaboration and partnerships between families, patients, and healthcare providers. The four concepts of family and patient centered care include: dignity, respect, participation and collaboration (Institute for Patient and Family - Centered Care, 2010). By providing this type of care, both families and patients will in turn be satisfied. In patient- and family-centered care, patients and families are encouraged and supported to participate in care and decision making at the level they choose. Research has shown that bedside report enhances patient-centered care by offering an opportunity to promote patient involvement and participation with their own clinical care (Chaboyer, McMurray, \& Wallis, 2010; Fenton, 2006). One way nurses can foster a more collaborative, patient and family-centered approach is to allow families and patients to participate in change-of-shift reporting through bedside reporting. This method of shift report puts patients and families at the center of care-related discussions and provides an environment for their questions, requests, or concerns to be addressed (Anderson \& Mangino, 2006).

A qualitative study by Tobiano, Chaboyer and McMurray (2012), explored families' perceptions of shift-to - shift bedside handover. The study was done surveying eight family members who currently had family members admitted to one rehabilitation ward in Queensland, Australia. Interviews were conducted as a guided conversation. The 
questions prompted responses. They asked the following: What do you think about the nurses doing bedside reporting at your relatives' bedside? What do you think your role is in the bedside handover and are there issues you feel should not be discussed in front of the patient? Three common themes emerged in the study. The first, understanding the situation; specifically, the patient's condition and treatment. Secondly, the interaction with nursing staff and lastly patients' self report of feeling at ease and feeling included in their plan of care. The researchers found that family members were able to inform nursing staff about pertinent information, showing a mutual respect and exchange which is a core part of the family - centered care approach. The researchers continue to say that family members felt they could clarify the information handed over at the bedside and then had the opportunity to clarify any inefficiencies and felt included in their care. The researchers concluded that bedside handover was an important way to promote family centered care.

Today patients want to be involved or at least informed about their own care, health- care options and other alternatives (Kravitz \& Melnikow, 2001). Bedside nurse reporting allows for patients to be active and in charge of their care. In an Italian hospice care center that participates in bedside report, families and patients were given a survey regarding their opinions of bedside reporting. This center had practiced bedside nursing for a long period of time and the organization was interested in obtaining feedback from patients on the current practice. Patients and family members reported an increased sense of safety and knowledge from the bedside nurse, allowing for a better overall experience (Wildner \& Ferri, 2012). 
Cairns et al (2013) conducted a project on a 23 bed trauma unit in Pennsylvania, measuring the value and importance of bedside report. The study was conducted using a model which is based on doing the right thing for every patient at all times. The unit used a self efficacy tool and conducted nurse surveys three months pre and three months' post implementing the change. Surveys from 29 nurses pre intervention and 18 nurses post intervention were analyzed. The overall outcomes were positive. Results showed an increase from $73.8 \%$ in the month of September, before bedside handover implementation, to $91.1 \%$ in December, 3 -months post implementation. The researchers found that call light usage decreased on the unit, nurse satisfaction increased, patient satisfaction increased, report was shorter, and overtime decreased. The reduction in call light usage during change of shift not only has the potential to contribute to patients' positive perceptions of nurses' response time but also has significant safety implications for the patient who is at risk for falling (Cairns).

Similarly, Anderson and Mangino (2006), evaluated the implementation of bedside report on a general surgical unit over a period of 8 months. The researchers found that patients' satisfaction increased after implementation of bedside reporting. Patients were satisfied that nurses kept them informed, that the staff worked better together to care for them, and that staff included them in decisions about their treatment. When patients feel this sense of autonomy in their care they feel better cared for and overall safer in their environment.

Ultimately as providers it is important that we meet patients' needs across the continuum. Collaborating with the patient and their families during report can prove to be useful, it can be a time to offer advice, support, and education for both staff and patients. 
In addition, nurses should always include patients' family when trying to assess the patient for issues such as delirium and baseline function and develop a plan of care for the patient and family as well (Steis, Shaughnessy, Gordon, 2012). In the end, patient centered care contributes to overall patient satisfaction.

\section{Patient satisfaction}

The Hospital Consumer Assessment of Healthcare Providers and Systems (HCAHPS) assesses patients on their experiences in the healthcare system. One of the several questions included is how well the nurses communicated with the patient or kept them informed (U.S. Department of Health \& Human Services (HHS), 2012). Even though this question is more specific to nurse-patient communication it also has implications related to hand offs. If pertinent pieces of information are missing during hand off, the oncoming nurse may appear less informed to the patient and thus affect their satisfaction in how well the nurse communicates with them (HHS, 2012).

Wakefield et al., (2012) conducted a quantitative study in a Midwest health center focusing on the transition to bedside report in hopes of improving patient satisfaction scores. A patient satisfaction survey was conducted six months before implementation and 23 months after implementation of bedside handover. Patients' participation ranged from 8 to 20 each month. The results were compared to satisfaction surveys from other hospitals on similar units. For the first six months after implementation, the patients' perceptions of nurses keeping them informed was high (94\%), compared with the entire 23 months $(87 \%)$, but patients' satisfaction was still above the pre-implementation baseline (83\%). What should be noted is that this study used a small convenience sample, with a low response rate. During the time of the study, 43 patient interviews were 
conducted in an attempt to determine the patients' perceptions of bedside report and how satisfied they were with the process. Seventy-two percent of surveyed patients revealed that they were highly satisfied with bedside report.

Freitag \& Carroll (2011), analyzed patient satisfaction scores on their 24- bed telemetry unit after employing bedside shift report over a three-month period. Client satisfaction scores were analyzed using the Press-Ganey measurement tool. The researchers found that bedside reporting contributed to a $4.9 \%$ increase in overall client satisfaction and a $6.5 \%$ increase in client perceptions of being informed of their care. The researchers determined that bedside report not only improved client communication but also facilitated patient collaboration and participation.

Kerr and McKinlay (2011) conducted a qualitative descriptive study and explored patients' perspectives of bedside handover in an emergency department in Australia. In total 30 surveys $(n=30)$ were collected from patients. The results indicated that bedside handover made patients feel less anxious because they knew that the nurses had a sufficient knowledge base about the condition, plan, and transition of care between shifts. Kerr's findings cited that when patients were able to listen during handover, they are more confident about the care they're receiving

Patients valued bedside reporting as an opportunity to receive information, to correct errors and give additional information regarding their current state of health and current condition (Lu et al., 2014). Lu et al. conducted a purposive sample study and interviewed patients $(n=30)$ in an Australian hospital (medical, surgical and maternity wards), and investigated perceptions about bedside handover. Patients expressed their need for information and a right to know about diagnoses and plans of care (Lu et al., 
2014) Patients felt that listening to report was an opportunity to obtain the information they needed to feel more confident and in control ( $\mathrm{Lu}$ et al).

\section{Barriers of Bedside Reporting}

Breaking the traditional routine of nursing report can be a challenge. Bringing report to the bedside requires both an adjustment and a practice change. Nurses may face several challenges when bringing report to the bedside and engaging patients and families in the exchange of information. Although the advantages of bedside reporting have proven to be plentiful, nurses still seem to have concerns regarding confidentiality which in turn leads to handover or reporting happening elsewhere, excluding patients from decision making about their own care (Kerr, 2011; Anderson et al, 2006).

Nurses still struggle to fully implement shift report at the bedside even with all the emerging evidence about the importance of actively involving the patient in bedside shift report (Sand-Jecklin \& Sherman, 2013). Nurses seem to be highly concerned with the breeching of confidentiality and HIPPA violations when other patients or family members are present in the room (Anderson \& Mangino, 2006; Cairns et al, 2013; Evans et al.,). Cairns et al. (2013), continues to say that not only are nurses uncomfortable with the privacy issues associated with bedside reporting, but the nurses also feel uncomfortable talking about tests or results that the physician has not yet discussed with the patient.

Some studies showed that nurses were concerned that patients would talk too long, ask too many questions, or ask for something in the middle of report that would then interrupt the report itself (Anderson \& Mangino, 2006; Evans et al., 2012). A study by Cairns et al. (2013), found a decrease in end-of-shift overtime by 10 minutes per day, 
or 61 hours per year, demonstrating an overall savings in overtime by $23 \%$. Street et al, 2013 stated "frequent interruptions" as barriers to bedside reporting (p.139). Although nurses feel as though bedside reporting is time consuming, reports have showed that bedside report is a relatively time efficient model (Fenton, 2006). Some nurses feel as though giving bedside report is a time when their nursing care is critiqued and at times felt uncomfortable giving verbal report in front of the patient to a seasoned nurse (Manias and Street, 2000). Some nurses worried that patients would ask questions that they could not answer. Also a lack of knowledge or confidence seemed to be another theme as to why nurses felt hesitant to perform bedside report (Burke, 2013).

A surgical colorectal oncology unit in New York, NY transitioned to bedside report after the Joint Commissions' 2009 recommendations for best safety practices. Bedside hand off and walking rounds occurred on the 43- bed surgical oncology unit. Thirty-three nurses were surveyed on what they felt worked and what didn't in regards to bedside report and then barriers were identified. The researchers found that report in the patients' room was not always completed because of unit distractions, such as call bells, phone calls and prioritization of clinical needs. In addition, nurses felt as though time was a constraint with many different degrees of interruption from patients and their family members (Taylor, 2015).

A surprising detail that was found in the literature was conveyed in a qualitative study by Caruso (2007) who found that although patients were satisfied with bedside report, they did not want to hear some information repeated multiple times per day, either because of redundancy or because they were too tired or anxious hearing about their health situation over and over (Caruso, 2007). 


\section{Sustainability of bedside reporting}

McMurray et al. (2010) determined that in order for change to be successful, those managing the change must be aware of nurses' attitudes, beliefs, concerns, and level of confidence, especially in the case of communicating the importance of bedside reporting. If the nurse feels as though bedside reporting has a role in the patients care it is more likely to be adopted. Hardwiring or adopting a new behavior takes time and attention over the long term and cannot be done with a quick fix (Studer, 2004). It is important then to periodically assess staff's attitudes and perceptions whenever a new change is implemented.

Bridges (2003), feels that people alone cannot control change but can control transition or how they respond to external change. Bridges, continues to say that as people go through a transition of change having a clear vision of the end goal is what keeps them focused. When implementing a big change like bedside reporting, it is crucial that staff understand the reasoning behind the change, the benefits and the overall process of how this new change will occur. Identifying change as a priority therefore can increases the chances of success and sustainability. Cairns et al. (2013) indicated that the implementation process is a difficult one and that "sustaining bedside shift report has not been without challenges and requires ongoing monitoring and encouragement" (p. 163)

Next the theoretical framework will be discussed. 


\section{Theoretical Framework}

A theory is a group of related concepts that propose action that guide practice. Theories increase the general body of knowledge within the discipline through the research implemented to validate them, and they are used to guide and facilitate nursing practice. Rogers' Diffusion of Innovations theoretical framework has been chosen for use with this project. Rogers' framework focuses on the concept of innovation, which he defined an as "any object, idea, technology, or practice that is new" (Rogers, 1995, p.17). According to Rogers (2003), innovations may be new objects, ideas or behaviors and diffusion occurs when these innovations are communicated though certain channels over time, among members of a social network.

Rogers' diffusion model describes five steps in the decision making process: knowledge; persuasion; decision; implementation and confirmation. In the knowledge phase, the individual is exposed to an innovation. The persuasion stage begins when the individual seeks information and information about the innovation. At the third stage of decision, an individual weighs the advantages and disadvantages of the innovation and decides to either adopt or reject the innovation. An individual employs the innovation and determines its usefulness in the implementation stage. In the confirmation stage, the individual finalizes his or her decision to continue using the innovation (Rogers, 1995). In Rogers's view, the relative advantage is the extent by which a particular group of users perceive innovation as better than the idea, or practice it replaces (Rogers, 1995). The bigger the perceived advantage of innovation by the organization or individual, the faster the level of its adoption will be (Rogers, 2003). Sometimes new practices, or clinical guidelines are easily implemented in practice, however most of the time, improving 
patient care is not easy, particularly if a new innovation requires complex changes in clinical routines. Rogers theory can help achieve better collaboration among disciplines, changes in patients' behavior, or changes in the organization itself.

Rogers's theory on adaptation and diffusion is a suitable theoretical model in the study of factors influencing the adoption of bedside reporting. Channels of communication used to disseminate information about an innovation include research publications, databases, mass media, and lectures. Face to face communication is suggested to be the most effective communication strategy. It provides an opportunity to tailor the delivery of information to recipients and discussion of the proposed change. Adoption of an innovation involves risk and uncertainty. Discussion with those who have adopted successfully often provides reassurance and credibility to the innovation (Rogers, 1995). With regards to bedside reporting when pursuing the implementation of a change in behavior or a new innovation, it is crucial to be aware of the elements of change.

Channels of communication used to disseminate information about an innovation include research publications, databases, mass media, and lectures. Face to face communication is suggested to be the most effective communication strategy due to the opportunity to tailor the delivery of information to recipients and discuss the proposed change. Adoption of an innovation involves risk and uncertainty. Discussion with those who have adopted successfully often provides reassurance and credibility to the innovation (Rogers, 1995).

Rogers describes five categories of adopters: Innovators; early adopters; early majority; late majority; and laggards. Innovators are the first individuals to adopt an innovation. They are often willing to take risks, young in age, in higher social and 
financial classes, and have close contact to scientific sources and other innovators. Early adopters are the second fastest in adopting an innovation and have a high degree of opinion leadership. They are also typically younger in age and of high social status. Early adopters are more discrete and judicious in adoption choices than innovators. The early majority are individuals who adopt an innovation after a varying degree of time. The early majority tend to be slower to make decisions but still have an above average social status. Individuals in the late majority group approach an innovation with a high degree of skepticism and adopt only after the majority of society has adopted. Laggards are the last group to adopt an innovation. The laggards have an aversion to change and are typically tradition focused. They are often older in age, have low social and financial status, and in contact with only family and close friends (Rogers, 1995). Rogers identifies five categories of adopters whose rate of adoption, when plotted, follows a normal distribution with standard deviations of a bell curve:

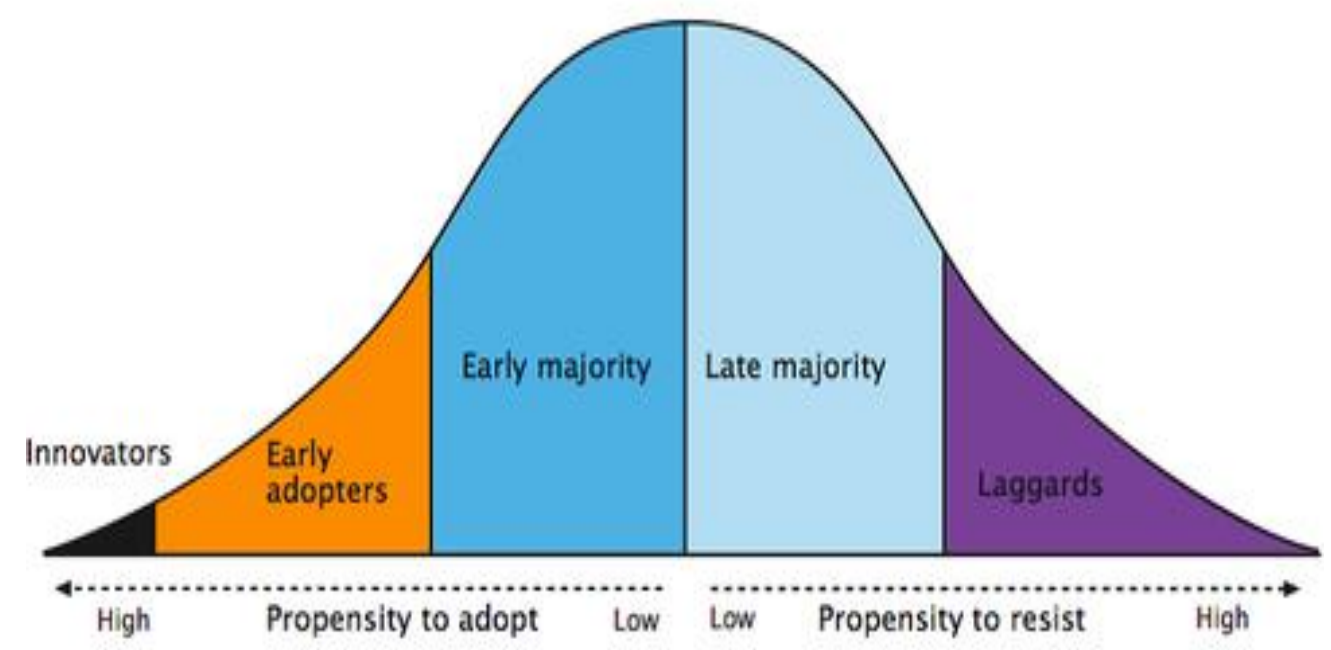

(Robinson, 2009).

Introducing innovations as a logically-related set of complementary innovationsan "interrelated bundle of new ideas" — can elicit more adoption decisions (Rogers, 
2003). Rogers argues that using a "package approach" makes sense intuitively and allows individuals to adapt to change quicker. He continues saying, once an individual's threshold is reached by her adoption of one innovation, her adoption threshold will be lower for subsequent or related innovations. If an innovation is simple and well defined, it is often more quickly adopted. One decision begets another, and another. The more integrated, the faster the rates of decision about innovations.

Application of this theory to bedside report provides a sound theoretical basis to operationalize its concepts. One major concept, innovation, provides the basis to communicate why the innovation (bedside report) works and is beneficial to the patient and nursing staff. As far as bedside reporting is concerned, a key to successful implementation is to communicate why the innovation works, not just what the innovation is. Rogers' theory is used several times in nursing literature, both in regards to innovation and change. By providing real and meaningful education, the learner's motivation is stimulated to solve the problem (Rogers, 1983).

Nurses in advanced practice must understand that no exact theory explains everything. Depending on the situation, certain theories may be more useful that others. The literature suggests that leadership, effective communication and team work are among the most important elements for planned change (Hewison and Stanton 2003, Jooste 2004, Schifalacqua et al 2009). Attempts to implement planned change face numerous barriers, but using a framework, such as Rogers', can help eliminate some of the potential problems, and address both the positive and negative aspects of the change. However, using a theory will not necessarily guarantee success. Whenever there is change, there is also room for failure. Getting a new idea adopted, even when it has 
obvious advantages, is difficult (Rogers, 2003). Rogers framework can help guide the new practice of giving report at the bedside. This theoretical framework is helpful when determining the adoption of specific clinical behaviors and when deciding which components will require additional effort if the diffusion is to occur. This project can provide insight into the perceptions nurses have about bedside reporting following implementation of the innovation. Rogers Diffusion of Innovation theory can be used to guide the development and implementation of bedside reporting by assisting nurses to understand the reasoning and advantages of report at the bedside. If a new proposed change is seen in a "negative" way, the innovation may not be implemented. On the other hand, if the recommended change increases satisfaction for the nurses and the patient the innovation may be readily adopted. Careful consideration of change theory can simplify the process and help those affected by change to be more receptive to it.

Next, the methods in the study will be presented. 


\section{Method}

\section{Purpose}

The purpose of this project was to explore nurses' perceptions on bedside reporting. The goal was to evaluate nurses' perceptions following the implementation of bedside reporting in the Trauma Intensive Care Unit.

\section{Research Questions}

What is the staff nurses' perceptions of bedside reporting in the Intensive Care unit following implementation?

\section{Design}

The research project utilized both a quantitative and qualitative design. The project surveyed nurses' perceptions of bedside reporting. The survey consisted of ten closed ended questions and one open ended question at the end that was analyzed for themes (Appendix A).

\section{Site}

The surveys were conducted in the Trauma intensive care unit (TICU) at Rhode Island hospital in Providence Rhode Island. Rhode Island Hospital is a non-profit 719bed acute care hospital. The hospital is a teaching facility affiliated with Brown University. The TICU is an 11 bed unit and has 36 registered nurses, one assistant clinical manager and one clinical nurse manager employed. The unit ratio is one nurse for one or two patients, depending on unit acuity. The unit has a mixture of single bed and double bed rooms. The unit was chosen because bedside reporting was implemented two 
years ago and the student researcher was interested in knowing why some nurses consistently participate while others are hesitant.

\section{Sample}

The project population consisted of both full time and part time RN nurses working in the TICU at Rhode Island Hospital. Inclusion criteria consisted of nurses working on the unit who have been involved in bedside reporting for the prior two years. There were $36 \mathrm{RN}$ nurses on the TICU, 33 of them will fit the inclusion criteria. In order to ensure adequate sample size for analysis, the goal was to have $40 \%$ participation or twelve nurses responding. Participants in the project remained anonymous and participation was done on a voluntary basis. The exclusion criterion included both nurse managers, nursing supervisors, and hospital administrators as well as travel nurses. No demographic data was collected due to possible compromise of identity on a such a small unit. The nurses who agreed to participate were given a survey regarding the prevalence, the benefits, and the barriers related to bedside report.

\section{Procedures}

A questionnaire composed of 10 closed-ended questions requiring a Likert scale response and 1 open-ended questions (Appendix A) was developed. The questionnaire was limited to two pages. Questions were closed-ended ranging from 1-5 ranging from “strongly disagree' (1) to 'strongly agree' (5). The neutral was represented by (3). Ordinal level data was collected. The questionnaire was developed at a sixth grade reading level. The questionnaire was evaluated for its content validity by a nurse manager, a quality safety nurse and a researcher professor. They both provided feedback on additional questions that should be included in the questionnaire. As a result, the 
following two questions were developed: Question 7: "Bedside report is completed at a reasonable time" and question 10:" I feel as though privacy is an issue with bedside reporting". An open ended question included at the end of the survey asked nurses whether they could provide any additional insight in regards to bedside reporting.

The Chief Nursing Officer (CNO) and the unit's clinical nursing manager provided both verbal and written permission for this project. Lifespan and Rhode Island College IRBs determined this project to be exempt. The clinical nursing manager was asked to forward an informational email (Appendix B) to staff and inform staff during meetings about the upcoming survey. Attached to the first page of each survey was an IRB approved informational letter describing the study purpose, procedures, and what is expected of participants. Contact information for the researcher, faculty member and principle investigator were also provided. Participants were assured that their participation was voluntary and responses were to be maintained anonymous and confidential. If they agree to participate, they were next asked to complete the attached survey and then drop it in a sealed box in the break room. Each nurse was given the option to decline participation without consequence and surveys were all anonymous. The student researcher was not present while the surveys were being taken and the surveys were not conducted in patient care areas. The surveys were available for two weeks. After the given two weeks, completed surveys were collected by the student researcher. All data was in a password protected computer that only the student researcher had access to. Data was stored in a folder labeled "Nurses' Perceptions of Bedside Reporting" and kept in a filing cabinet at that only the Principal researcher had access to. 


\section{Measurement}

A 10 question survey (Appendix A) was developed from various different researchers with two additional questions added based on their theories as to why bedside reporting has been difficult to sustain at times. Content ideas identified in the survey consisted of ten questions with a five-point Likert response format and one open-ended question; the Likert responses ranged from $1-5$, with $1=$ strongly disagree and $5=$ strongly agree. Content ideas assessed nurses' perception of bedside reporting; the purpose of use, importance of use, and impact on practice. One open ended question at the end looked for insight on any additional information that the $\mathrm{RN}$ could give about the process and to better understand nurses' perceptions of how bedside reporting could be more widely adapted.

\section{Ethical Considerations}

There were no ethical considerations noted while conducting this quality improvement project. There were no patients involved in the project and all the nurses who participate did so on a voluntary basis. All the participants were given an information sheet about the project.

The project manager works on the unit and possibly staff might feel some pressure to participate in the survey. Both males and females were included in survey participation. There was no discrimination of participants related to age, race, ethnicity or gender. Surveys were anonymous and do not contain any participant identifiers. 


\section{Organizational Factors}

Nursing leadership were very supportive of educational projects. The institution as a whole has supported continuing education and advancement of nursing degrees. Facility barriers were that the survey was completed on a small closed unit where privacy is a bit more difficult. The small unit resulted in a small sample size. The institution itself has taken pride in building strong inter-professional teams among nurses and is open to research and support projects currently being done.

\section{Data Analysis}

Questionnaire data were collected and managed using REDCap (Research Electronic Data Capture) tool hosted by Lifespan. REDcap is a secure, web-based application to support data capture for research studies, providing 1) an intuitive interface for validated data entry; 2) audit trails for tracking data manipulation and export procedures; 3) automated export procedures for data downloads to a common statistical package; and 4) procedures for importing data from external sources. Basic descriptive statistics was performed on all survey data. The open-ended question was analyzed for emerging patterns and/or themes.

\section{Timeline}

Proposal to Lifespan IRB was submitted October 30, 2016 and the RIC IRB March 1, 2017. Timeline of the research was from March 10, 2017 to March 24, 2017. Completion of report and findings by April 30, 2017. Presentation of project May 2, 2017.

Next, the study results will be presented. 


\section{Results}

Overall, the study yielded a higher than expected response rate. Thirty-two nurses out of a potential thirty-six nurses on the project unit $(\mathrm{N}=32,88 \%)$ completed the 10 question survey. The project unit nurses expressed their willingness to participate freely in the project and felt like it would be useful to the unit. Nurses told the student researcher "I look forward to hearing the results". Positive feedback from nurses shared with this student researcher included "thank you for doing this I actually feel like we do it now more since your started this and "Thank you, I remind myself everyday to get up and do bedside report now". Following the 10 questions, there was one open ended question that attempted to gain more insight into the overall process. Nurses were asked to write anything they felt about bedside reporting. A total of ten RNs (31\%) responded. The following are representative of some of their responses. Some of the nurses wrote more than one responses. These are shared here.

- "Bedside nursing is great for giving your patient a once over and ensuring all safety equipment is in the room"

- "I like bedside reporting however sometimes it can take too long and patients confidentiality can be compromised especially if they are in a double room"

- "Some patients have sensitive social issues that make it hard to do bedside report in front of them"

- "Bedside report is beneficial in many ways but also has its downside, I feel as though patients can misconstrue some of the information they hear which can be upsetting to them" 
- “Although I like it, some matters are more sensitive and I don't feel like it should be discussed in front of the patient"

- "Patients develop a "laundry list" of needs whenever staff is present which is difficult to start the day this way"

- "Being a newer nurse in a critical care setting I feel more comfortable having a visual of the patient at the same time as report"

- "Too many frequent interruptions but I think it improves safety for sure"

- "We should all be doing it, and I feel like I see more people doing since we have started for sure"

- "Has its good points and bad like anything else we try"

- "I feel like patients can get sick of hearing the same thing over and over again "

- "I can usually meet their basic needs right away, and this I like"

Overall themes in the responses identified positive aspects of patient safety with bedside reporting but discussed negative aspects related to time demands, concern for patient privacy and discomfort addressing some sensitive patient issues on a face to face basis.

The following graphs on the next few pages illustrate the survey questions and the number of participants who responded to each question. 


\section{Graph 1}

Question: Bedside report is an effective means of communication.

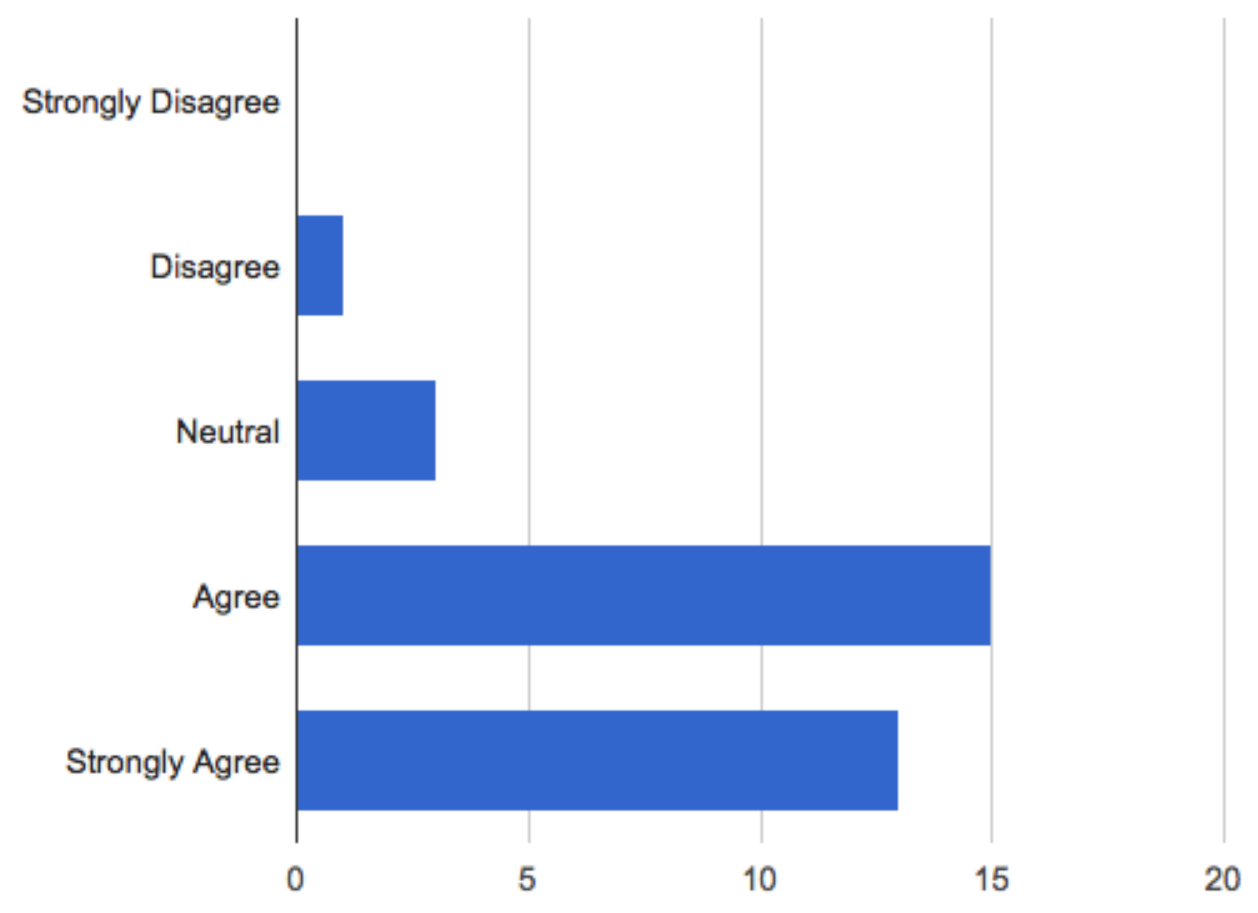

Counts/frequency: Strongly Disagree (0, 0.0\%), Disagree (1, 3.1\%), Neutral (3, 9.4\%), Agree (15, 46.9\%), Strongly Agree (13, 40.6\%)

The question "Bedside reporting is an effective means of communication" resulting in a mean of 4.3 , with $87.5 \%$ of nurses responding positively with agree or strongly agree. Very few nurses felt negatively about bedside reporting in regards to communication. 


\section{Graph 2}

Question: Bedside report helps assure accountability between peers in effectively communicating patient information.

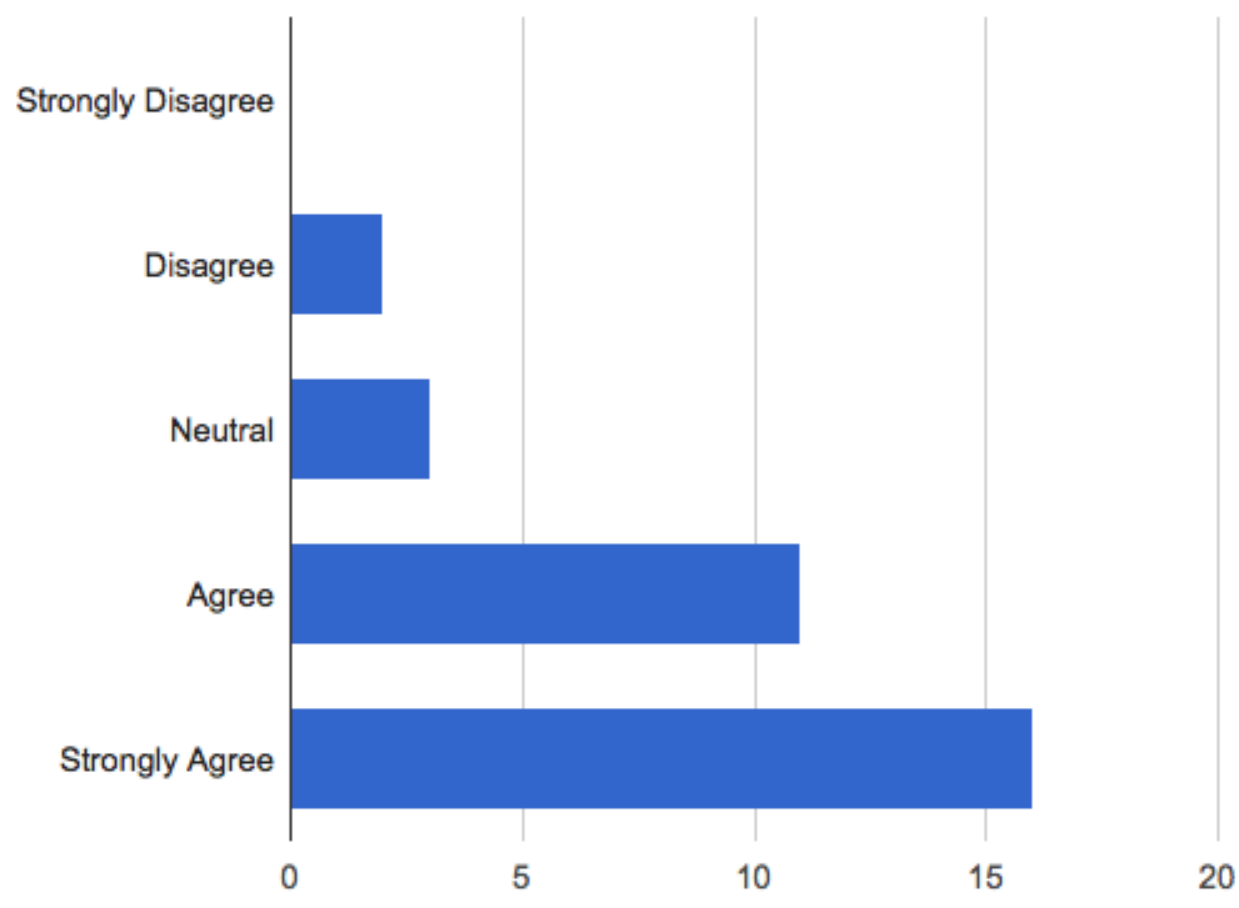

Counts/frequency: Strongly Disagree (0, 0.0\%), Disagree (2, 6.3\%), Neutral (3, 9.4\%), Agree (11,34.4\%), Strongly Agree (16, 50.0\%)

Graph 2 evaluates the question "Bedside report helps assure accountability between peers effectively communicating patient information". Approximately $84.4 \%$ of nurses answered agree or strongly agree to this question. There were no responses in the strongly disagree category. $15.7 \%$ of participants either responded neutral or disagree to the question. 
Graph 3

Question: Bedside report gives opportunities for mentoring new staff.

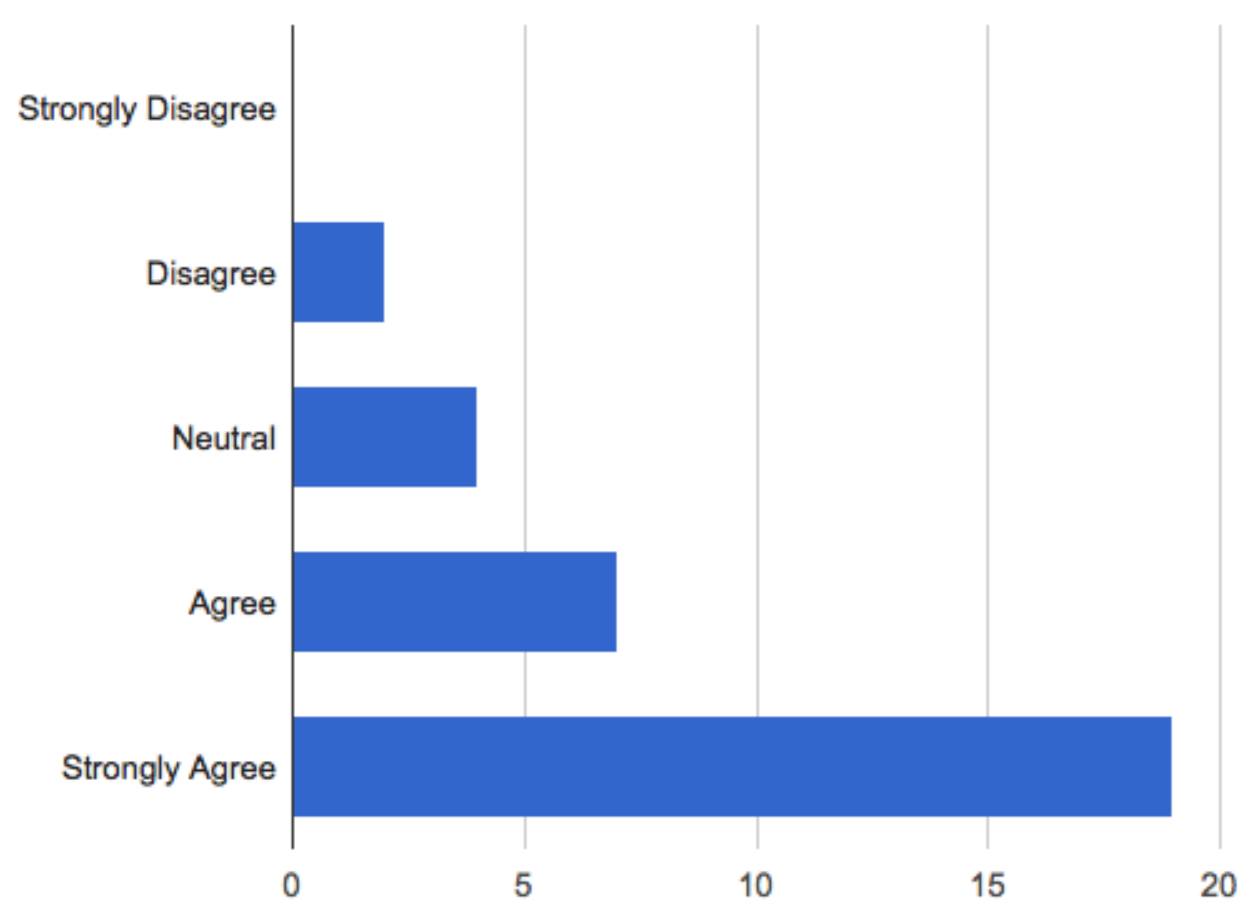

Counts/frequency: Strongly Disagree (0, 0.0\%), Disagree (2, 6.3\%), Neutral (4, $12.5 \%)$, Agree (7, 21.9\%), Strongly Agree (19, 59.4\%)

Graph 3 illustrates a strong response to the question: "Bedside reporting gives opportunities for mentoring new staff". Combined $81.3 \%$ of the staff agreed and strongly agreed to this question, $6.3 \%$ disagreed and zero strongly disagreed. As of note $12.5 \%$ of staff remained neutral to this question. 
Graph 4

Question: Bedside report promotes patient involvement in care.

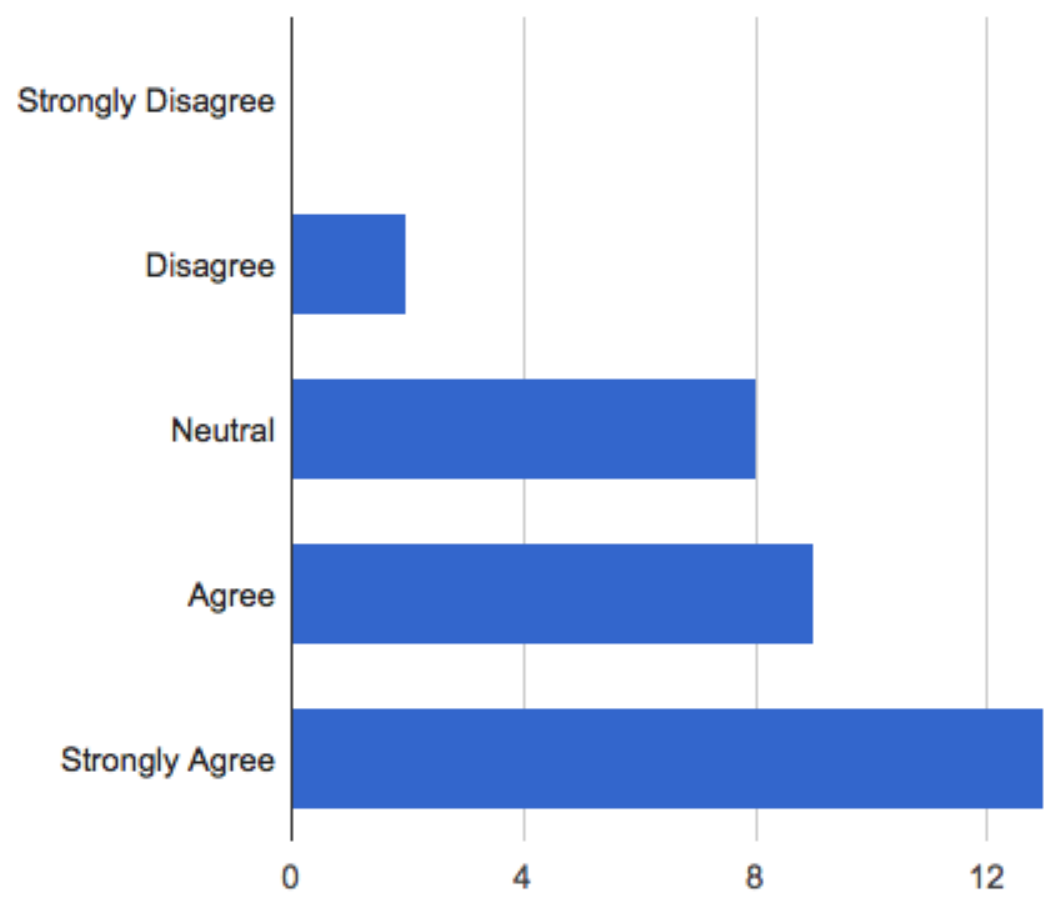

Counts/frequency: Strongly Disagree (0, 0.0\%), Disagree (2, 6.3\%), Neutral (8, $25.0 \%)$, Agree $(9,28.1 \%)$, Strongly Agree $(13,40.6 \%)$

The question "Bedside report promotes patient involvement in care" seemed to produce a more neutral response in which $25 \%$ of nurses answered neutral, $28.1 \%$ of nurses agreed, and $40.6 \%$ strongly agreed. We should make note here that no one chose strongly agreed in this category. 


\section{Graph 5}

Question: Bedside report improves patient safety.

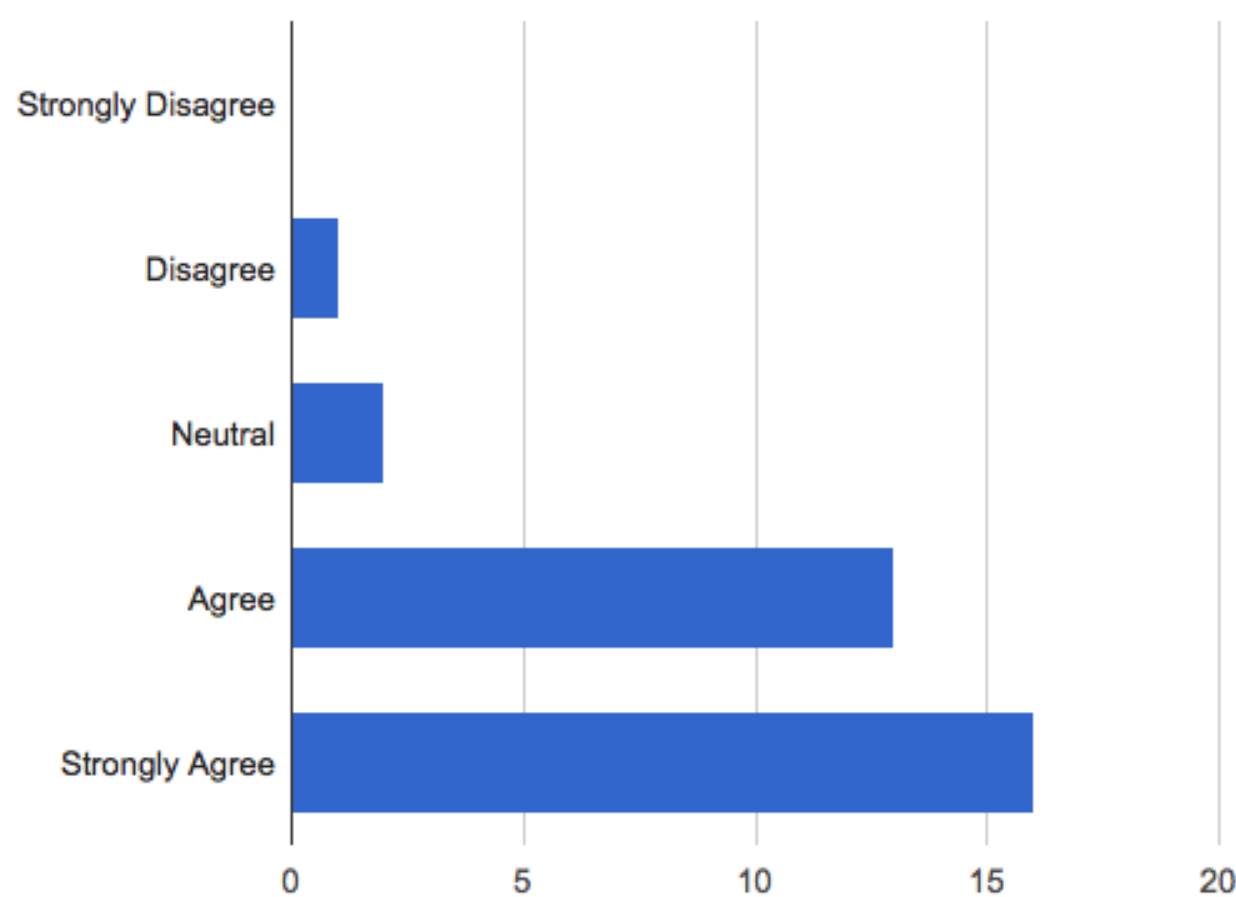

Counts/frequency: Strongly Disagree (0, 0.0\%), Disagree (1, 3.1\%), Neutral (2, $6.3 \%)$, Agree (13, 40.6\%), Strongly Agree (16, 50.0\%)

As reflected in Graph 5, over $90.6 \%$ of participants agreed or strongly agreed that bedside reporting improves patient safety. This question received the overall highest rating within the survey reflected by a 4.4 mean. 
Graph 6

Question: Bedside report helps me feel better informed about my patients.

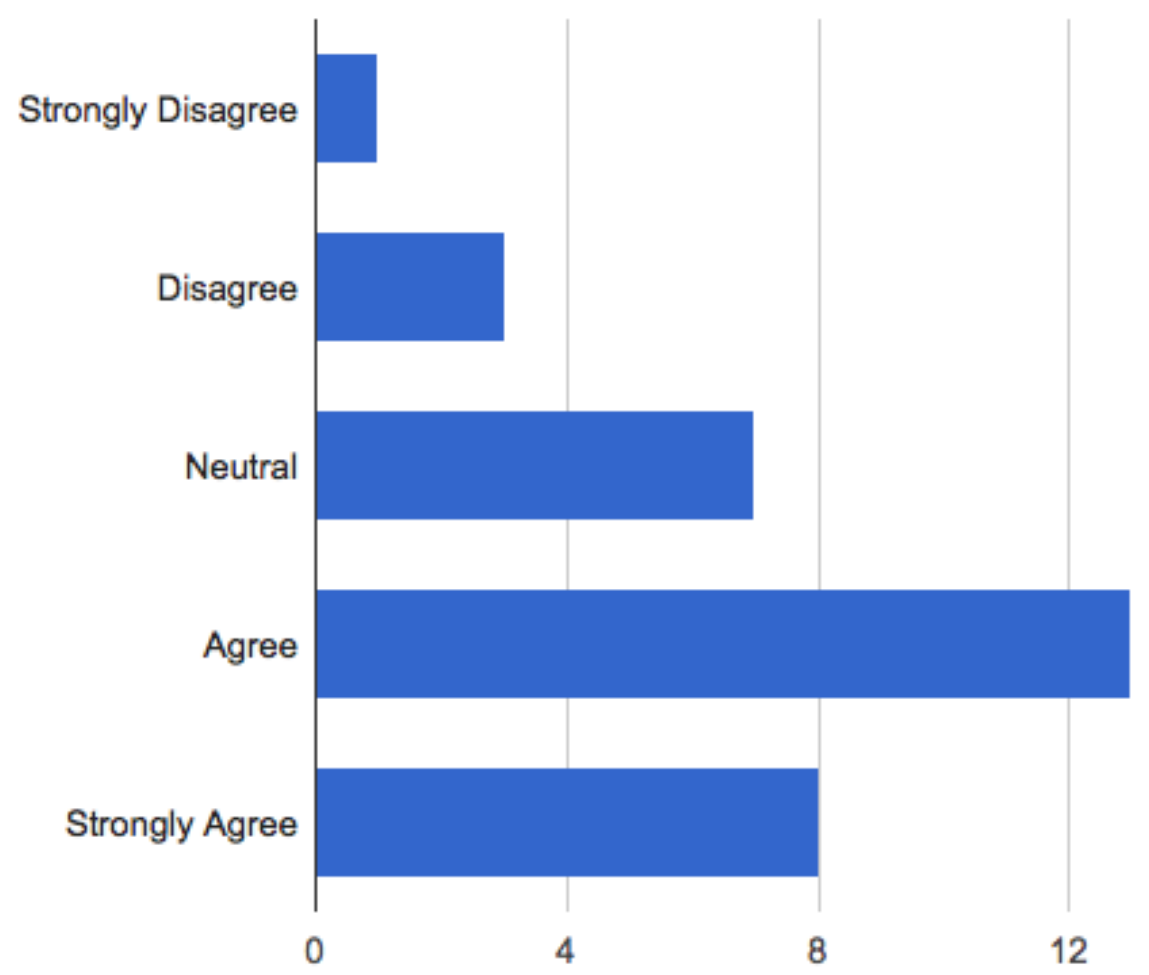

Counts/frequency: Strongly Disagree (1, 3.1\%), Disagree (3, 9.4\%), Neutral (7, $21.9 \%)$, Agree (13, 40.6\%), Strongly Agree (8, 25.0\%)

Graph 6 shows results to the question "Bedside report helps me feel better informed about my patients" In the strongly agree/agree group a total of $65.6 \%$ of nurses felt this was true. As of note $21.9 \%$ remained neutral and $9.4 \%$ disagreed, while $3.1 \%$ strongly agreed. 


\section{Graph 7}

Question: Bedside report is completed in a reasonable time.

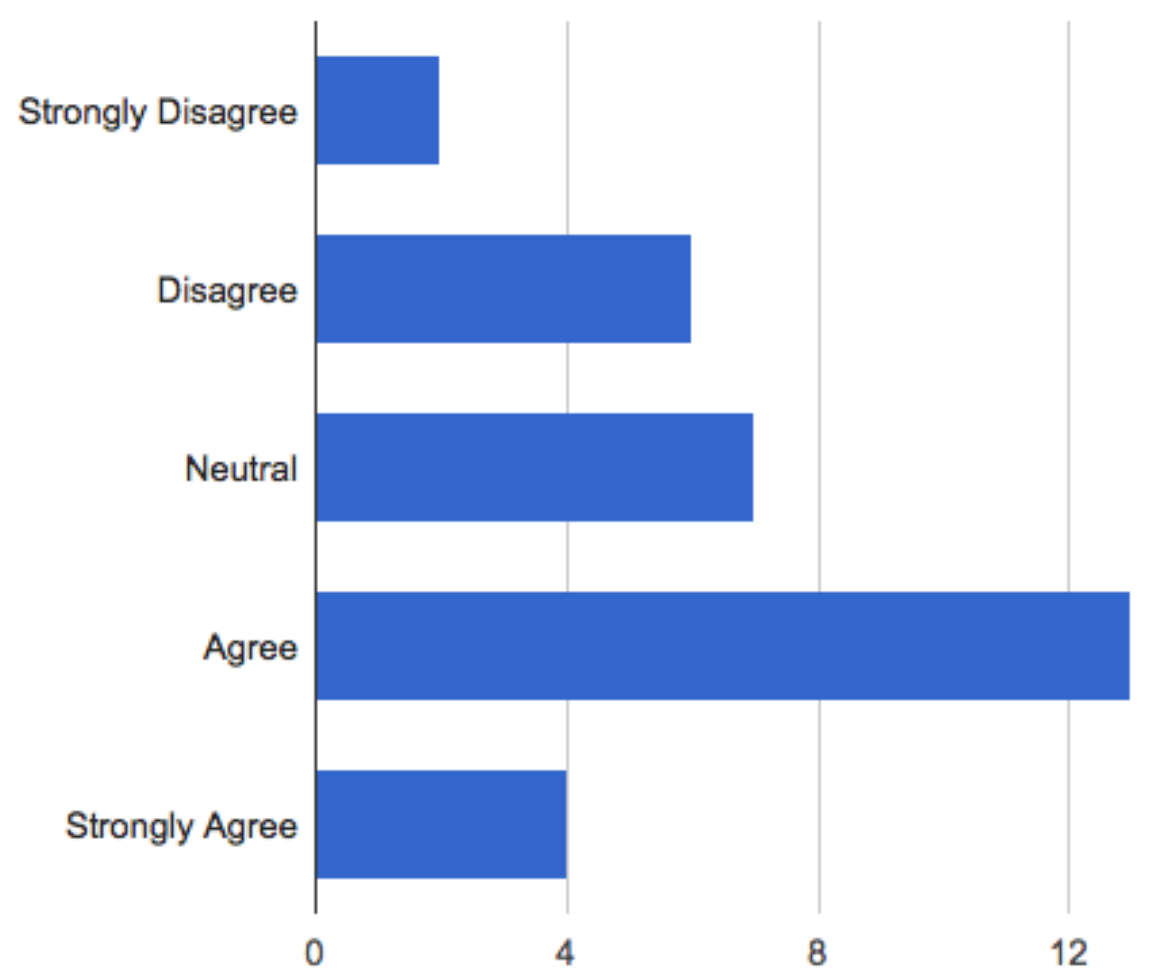

Counts/frequency: Strongly Disagree (2, 6.3\%), Disagree (6, 18.8\%), Neutral (7, $21.9 \%)$, Agree (13, 40.6\%), Strongly Agree (4, 12.5\%)

Graph 7 asks the question "Bedside report is completed in a reasonable time". Responses showed the most varied results amongst all survey questions. $81.2 \%$ of responses fell into the middle between agree and disagree. 


\section{Graph 8}

Question: I practice bedside report regularly

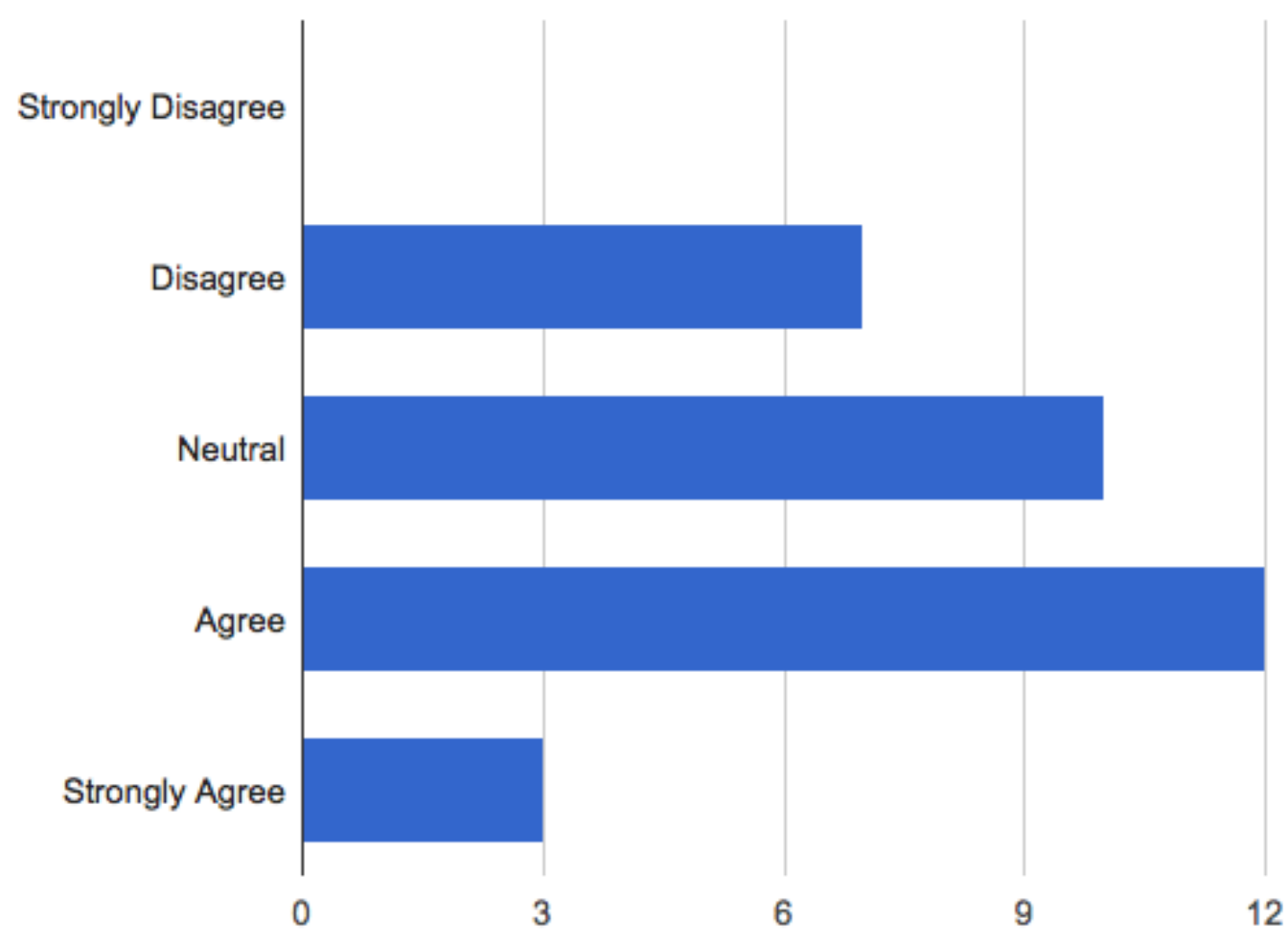

Counts/frequency: Strongly Disagree (0, 0.0\%), Disagree (7, 21.9\%), Neutral (10, $31.3 \%)$, Agree (12, 37.5\%), Strongly Agree (3, 9.4\%)

Question 8 asks participants if they "practice bedside report regularly". Results show the highest concentration in neutral response at $31.3 \%$ and shared the second lowest mean of survey responses at 3.3. 
Graph 9

Question: Overall, I like face-to-face interaction with the patient during bedside reporting.

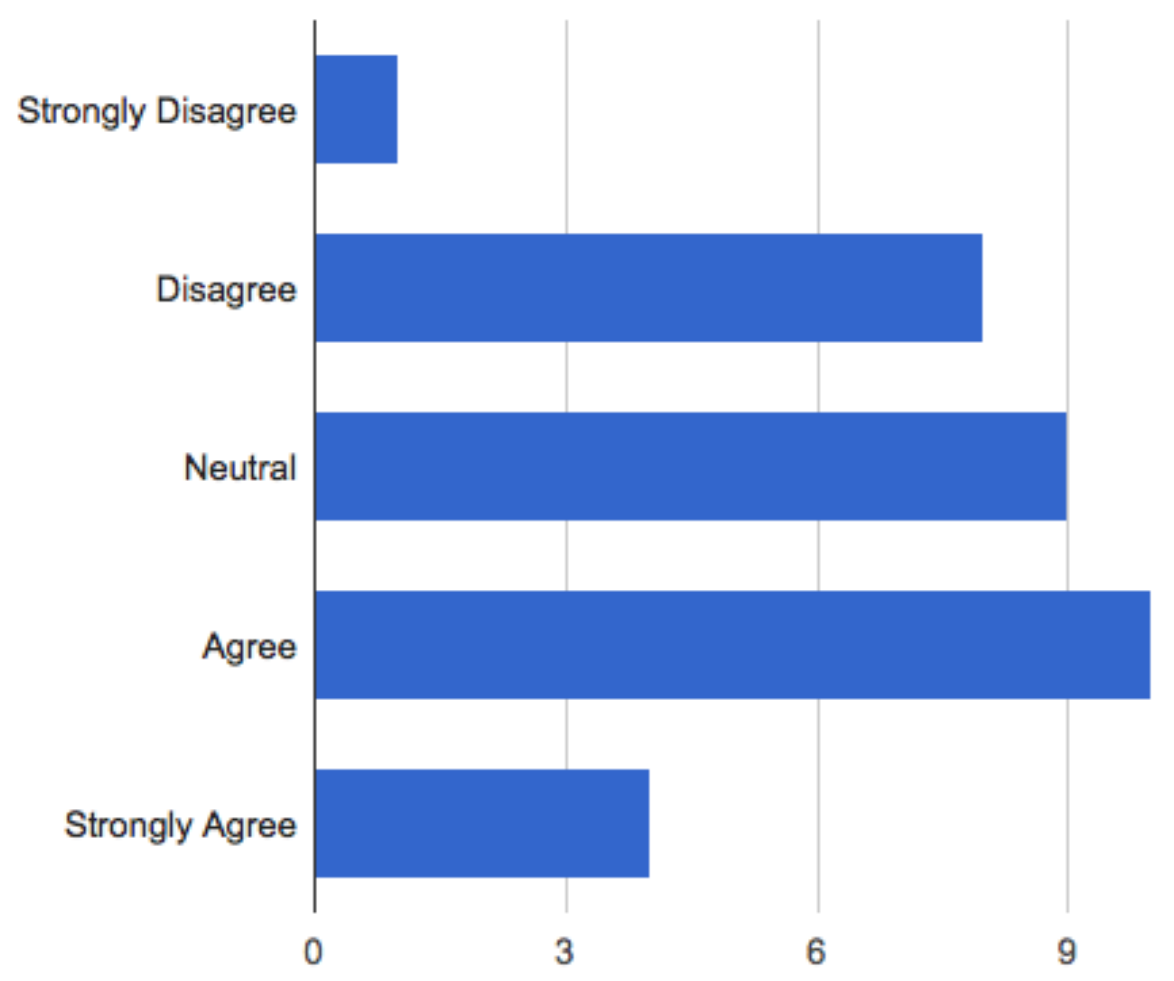

Counts/frequency: Strongly Disagree (1, 3.1\%), Disagree (8, 25.0\%), Neutral (9, $28.1 \%)$, Agree (10, 31.3\%), Strongly Agree (4, 12.5\%)

Graph 9 asks the question "Overall, I like the face to face interaction with the patient during bedside reporting. This question yielded the highest percentage of either disagree or strongly disagree at $28.1 \%$, with the lowest mean of the survey results at 3.25 . 
Graph 10

Question: I feel as though privacy is an issue with bedside reporting.

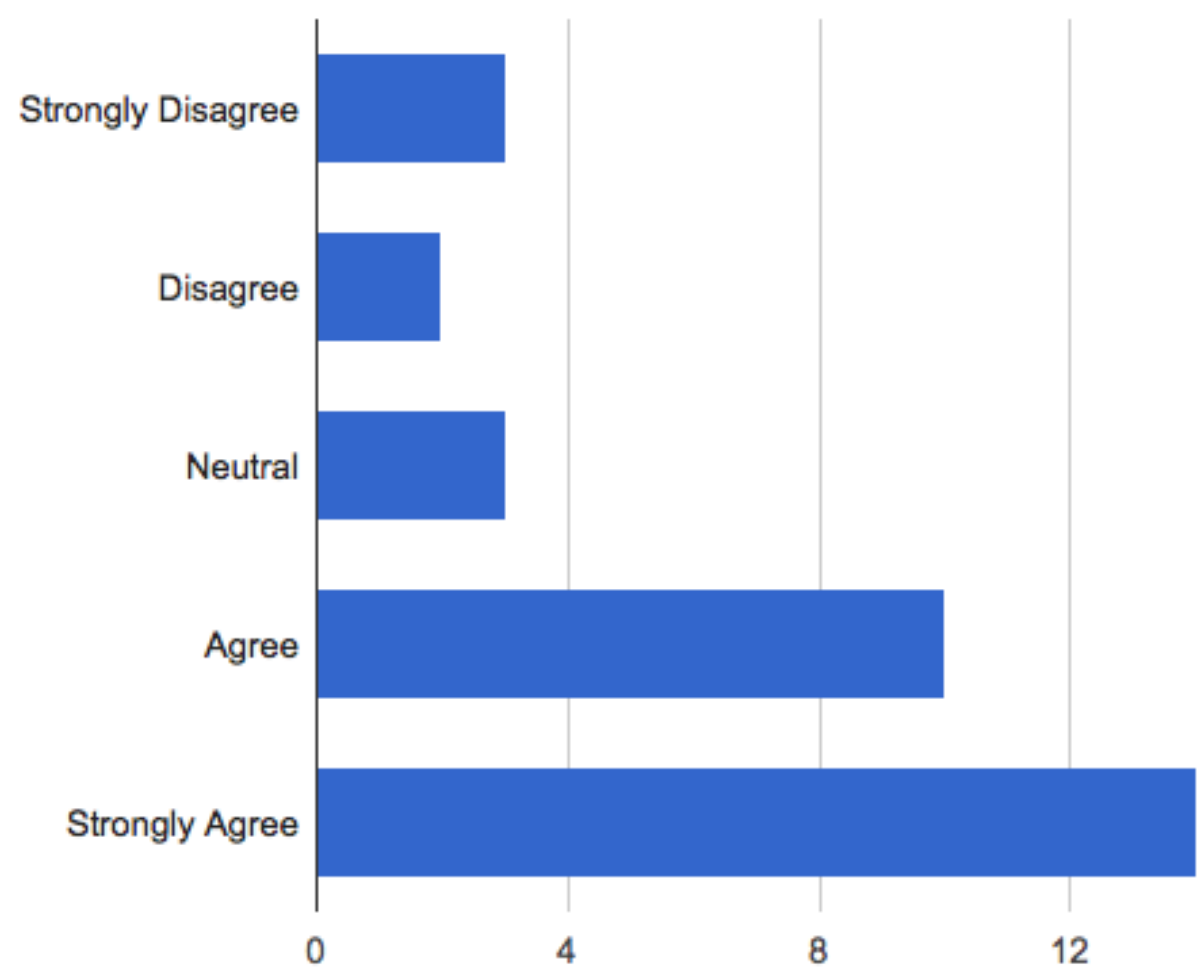

Counts/frequency: Strongly Disagree (3, 9.4\%), Disagree (2, 6.3\%), Neutral (3, 9.4\%), Agree (10, 31.3\%), Strongly Agree (14, 43.8\%)

Graph 10 Illustrates a large number of nurses acknowledging that privacy is a big issue in regards to bedside reporting. $75.1 \%$ of nurses agreed and strongly agreed that privacy was a concern as a whole, however $15.6 \%$ of participants responded negatively with disagree or strongly disagree. 
Table 1 illustrates the survey questions and results of the $\mathrm{N}=32$ participants Survey Responses

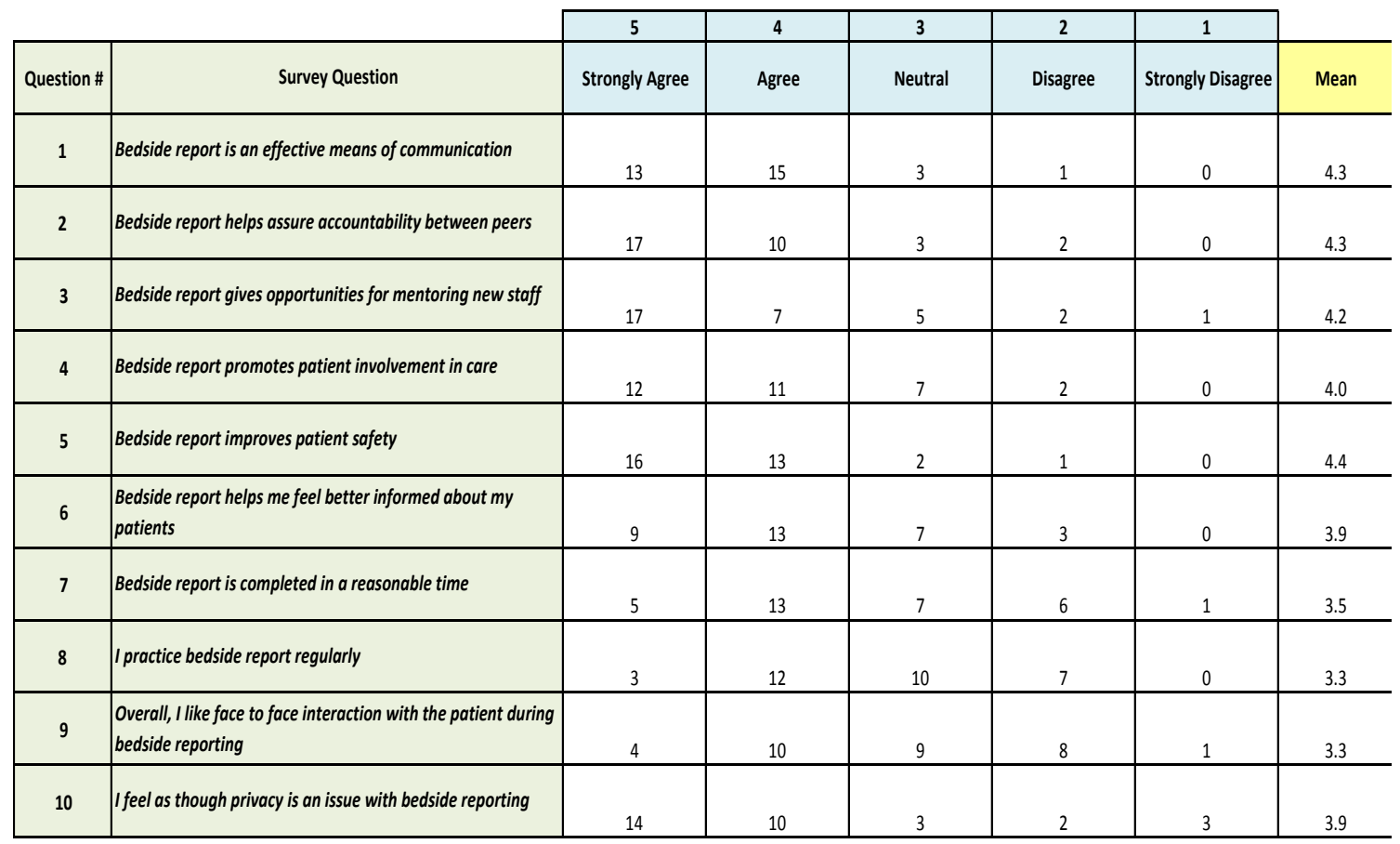

\section{Discussion}

Survey results showed that participants rated improved safety, effective communication strategies, accountability for staff and mentoring new staff as the most significant improvements with bedside reporting. With this being said, only $53 \%$ of nurses acknowledged that they practiced bedside report regularly. One can theorize that there are various explanations for this. As seen by some of the responses in the open ended question, some feel that "its too time consuming", "it's a privacy concern", "its patient dependent" etc. Approximately $75 \%$ of nurses identified that privacy was a big issue with this type of reporting, especially if the patient was in a double room with another patient. 
Approximately $56.2 \%$ of participants identified that they did not strongly agree or agree with question number 9 which asks if the nurse likes the face to face interaction with the patient during report. One may speculate that the uneasiness is due to a lack of knowledge in effective communication. Perhaps informing the patient of the bedside reporting process could assist communication on both ends between the patient and the nurse and minimize interrupted report. Some nurses claimed it took "too much time", or that patients had a "list of needs" and they just wanted to finish report. Participants were also asked to describe, in short answer form, if they had anything else to add about the process of bedside reporting; what they perceived to be positive or negative or overall how they felt about the process. Although the responses were mixed, a common theme emerged when looking at the short answers collectively. The 10 nurses who responded to this question mostly identified privacy as being a concern and the fact that they felt "uncomfortable" giving sensitive information in front of the patient if they were in a double room. Some nurses felt that patients could misconstrue what was being said and that patients got "easily upset" if they hear the wrong information. On the other hand, novice nurses appreciated doing bedside report especially when handing off to a seasoned nurse; they felt it was an opportunity to identify something they could have improved, and sometimes more seasoned nurses could identify an error on their behalf. Surprisingly, although most $(81.3 \%)$ felt that this was an opportunity to mentor new staff, one nurse commented on the survey that when they point out someone's inaccuracies it can be seen as a form of "incivility" to some.

Questions 8 and 9 ask the survey participants directly about how they themselves utilize bedside reporting. Interestingly enough survey results favor a neutral response. 
These two question have the highest percentage of "neutral" throughout the survey. This is an interesting finding since bedside reporting has been "in practice" for the past two years. It highlights the need to sustain the initiative through ongoing evaluation and education of the process and the consistency in practice.

Several limitations existed for this project. First, the sample size was limited by the small size of the unit and exclusion criteria prevented new nurses/per diem/travel nurses from participating. This sample size may not accurately represent the population of nurses who have undergone a similar process change, but it does represent the perception of the nurses on this unit with enough experience to compare. A second limitation included no collection of demographic data. In an effort to keep survey responses confidential, no identifying information was collected in this small group. The concern was that some nurses would not answer if they new identifiers were in play, however demographic data could have allowed for correlations between years of experience and perceptions of this type of reporting. 


\section{Summary and Conclusions}

As a National Patient Safety goal identified by The Joint Commission, improved communication is a top priority for healthcare facilities. Although a number of different hospitals and units are already practicing bedside reporting on a daily basis, it is crucial that other units follow suit. Requiring standardization of handoff to improve patient safety has resulted in many process changes for nursing handoff. In summary, a problem identified in nursing practice is the lack of universal guidelines for nurses to follow when giving nursing report. As shown in the literature review, there are few standardized guidelines for nurses to follow. In addition, several barriers were identified in implementing and maintaining the practice of bedside reporting. The purpose of this research project was to determine nurses' perceptions of bedside reporting in an intensive care setting where bedside reporting was implemented on the unit two years prior.

Participants were adult critical care registered nurses who were employed on the trauma intensive care unit at Rhode Island Hospital. Of the eligible 36 participants, 32 completed the survey (88\%). The nurses were asked to complete a survey using Likert responses to describe their perception of the usefulness of bedside reporting.

Survey results showed that participants rated improved safety, effective communication strategies, accountability for staff and mentoring new staff as the most significant improvements with bedside reporting. With this being said, only $53 \%$ of nurses acknowledged that they practiced bedside report regularly. One can theorize that there are various explanations for this. As seen by some of the responses in the open ended question, some feel that "its too time consuming", "it's a privacy concern", "its patient dependent" etc. 
Approximately $75 \%$ of nurses identified that privacy was a big issue with this type of reporting, especially if the patient was in a double room with another patient. Approximately $56.2 \%$ of participants identified that they didn't strongly agree or agree to the face to face interactions with their patients during report. Some nurses claimed it took "too much time", or that patients had a "list of needs" and they just wanted to finish report. Participants were also asked to describe, in short answer form, if they had anything else to add about the process of bedside reporting; a common theme emerged when looking at the short answers collectively. The 10 nurses who responded to this question mostly identified privacy as being a concern and the fact that they felt "uncomfortable" giving sensitive information in front of the patient if they were in a double room.

Question 8 "I practice bedside reporting regularly", showed only $46.9 \%$ of participants agreed or strongly agreed to this question. This response showed that a lack of consistency in the practice of bedside reporting existed.

Several limitations existed for this project. First, the sample size was limited by the small size of the unit and exclusion criteria prevented new nurses/per diem/travel nurses from participating. A second limitation included no collection of demographic data. In an effort to keep survey responses confidential, no identifying information was collected in this small group. The concern was that some nurses would not answer if they knew identifiers were in play Demographic data could have allowed for correlations between years of experience and perceptions of this type of reporting.

Effective hand offs can have a significant impact on several measurable outcomes related to patient care. The most significant outcome impacted by effective hand offs is 
that of patient safety. The Joint Commission has already emphasized this by making clear communication one of its National Patient Safety Goals. In conclusion, the majority of the participants identified bedside reporting as a safe and effective way of communication and that bedside reporting improved the consistency of information exchanged. Participants liked that there was the opportunity for accountability between staff members and there were opportunities to mentor new staff. Nurses identified privacy as a big issue when reporting at the bedside and at times felt uncomfortable talking in front of the patient and family members when it came to sensitive topics. Nurses did not think that bedside reporting saved too much time, some actually felt it was a little too time consuming if the patient or families had too many questions or needs. Evidence proves that bedside reporting help to decrease time and improve patient satisfaction (Andersen $\&$ Mangino, 2006 \& Thomas \& Donahue-Porter, 2012) so it is crucial to overcome barriers and continue this process on the unit. Interestingly, many nurses admitted to not enjoying the face to face interaction even though they understood and felt themselves that the process of bedside reporting improved safety and communication. When asked in the open ended question what they thought overall about the process, most responses included about privacy being a constant issue and that bedside reporting is a great thing depending on the patient population. Further research on the practice and sustainability of bedside reporting is indicated. Recommendations and implications for advanced nursing practice are presented next. 


\section{Recommendations and Implications for Advanced Nursing Practice}

Successfully adopting any new change requires extensive work from staff and leadership throughout the healthcare system. The Advanced Practice Registered Nurse (APRN), is uniquely prepared to facilitate adaptation to a new practice such as bedside reporting by providing evidence based education that shows positive outcomes on patients across the continuum in the hospital setting. New transitions can be difficult to coordinate and require the expertise of an advanced practice nurse to help facilitate an evidence based recommendation into practice. Success of sustaining the process of bedside report is largely dependent on planning, support during implementation, and post implementation evaluation optimization and follow through. Frequent meetings and consultations with staff to evaluate what is working and what is not is critical to sustainability. Through ongoing communication and evaluation, the APRN can identify the need for refinement or reinforcement of the change in practice.

Advanced Practice Registered Nurses are in an ideal role to assume responsibility as change agents. They can assist in comprehensive training for staff before implementation, during and after a new initiative. The APN has the skills to evaluate the new initiatives and provide sound recommendations for needed adjustments. As part of the role, the APN has the ability to collaborate with a variety of health care providers. This enables the APN to establish best practices for patient care improvement. Research skills provide the APN with the ability to evaluate new practices, critique new research and conduct sound research studies to help produce the most positive patient outcomes.

The APN serves as a resource to staff and an advocate for safe patient care. As a facilitator of communication and collaboration, the APN can help the system to reach the 
improved safety goals established by the national safety organizations. The APN has an important role in being an advocate for patients and families. Sharing the patient perspective with other health care providers can assist in fostering a strong patient relationship that is culturally sensitive. This support can lead to improved patient satisfaction. As importantly, the supportive role to staff in listening to and soliciting their ideas and concerns will help to improve nurses' satisfaction and mentor them in their own efforts to improve practice.

The Joint Commission continues to state improved effectiveness of communication among caregivers as a national patient safety goal in 2016. The Agency for Healthcare Research and Quality (AHRQ) and the Joint Commission Center for Transforming Healthcare have had workshops and toolkits to assist facilities in implementing bedside reporting (Joint Commission Center for Transforming Healthcare, 2015; AHRQ, 2013). The Advanced practice nurse is a key leader in utilizing these tools for a nurse driven change in culture.

Advanced practice nurses across the nation can provide leadership in improving communication that enhances patient safety, including ensuring that nurses are able to perform bedside report in an effective manner. Constant, open communication needs to occur between all team members so that changes are anticipated and information can be provided as to what works best for all in the practice setting. 


\section{References}

Agarwala, A. V., Firth, P. G., Albrecht, M. A., Warren, L., \& Musch, G. (2015). An electronic checklist improves transfer and retention of critical information at intraoperative handoff of care. Anesthesia \& Analgesia, 120(1), 96-104.

Agency for Healthcare Research and Quality. Nurse bedside shift report implementation handbook. Retrieved from http://www.ahrq.gov/professionals/systems/hospital/engagingfamilies/strategy3/St rat3_Implement_Handbook_508.pdf.

Anderson, C. D., \& Mangino, R. R. (2006). Nurse shift report: Who says you can't talk in front of the patient? Nursing Administration Quarterly, 30(2), 112-122.

Athwal P, Fields W, Wagnell E. Standardization of change-of-shift report. Journal of Nursing Care Quality. 2009;24:143-147.

Bridges W, ed. Managing Transitions: Making the Most of Change. 2nd ed. Cambridge, Mass: Da Capo Press; 2003.

Burke W, McLaughlin D. Partnering for Change. The American Journal of Nursing. 2013;113(2):47- 51.

Cairns, L. L., Dudjak, L. A., Hoffmann, R. L., \& Lorenz, H. L. (2013). Utilizing bedside shift report to improve the effectiveness of shift handoff. Journal of Nursing Administration, 43(3), 160-165. doi: 10.1097//NNA.0b013e318283dc02

Caruso, E. M. (2007). The evolution of nurse-to-nurse bedside report on a medicalsurgical cardiology unit. Medsurg Nursing, 16(1), 17.

Chaboyer, W., McMurray, A., Johnson, J., Hardy, L., Wallis, M., \& Chu, F. Y. S. (2009). 
Bedside handover: Quality improvement strategy to "transform care at the bedside." Journal of Nursing Care Quality, 24(2), 136-142. doi: 10.1097/01.NCQ.0000347450.90676.d9

Chaboyer, W., McMurray, A., \& Wallis, M. (2010). Bedside nursing handover: A case study. International Journal of Nursing Practice, 16(1), 27-34.

Cornell, P., Townsend Gervis, M., Yates, L., \& Vardaman, J.M. (2013). Improving shift report focus and consistency with the situation, background, assessment and recommendation protocol. The Journal of Nursing Administration, 43(7), 422428. http//dx.doi.org/10.1097/NNA.0b013e31829d6303

Evans, D., Grunawalt, J., McClish, D., Wood, W., \& Friese, C. R. (2012). Bedside shiftto-shift nursing report: Implementation and outcomes. Medsurg Nursing, 21(5), 281-4. Retrieved from http://www.medsurgnursing.net

Fenton, W. (2006). Developing a guide to improve the quality of nurses' handover. Nursing older people, 18(11), 32-37.

Freitag M. \& Carroll S. (2011) Handoff communication: using failure modes and effects analysis to improve the transition in care process. Quality Management in Health Care 20(2), 103-109.

Friesen, M. A., Herbst, A., Turner, J. W., Speroni, K. G., \& Robinson, J. (2013). Developing a patient-centered ISHAPED handoff with patient/family and parent advisory councils. Journal of Nursing Care Quality, 28(3), 208-216.

Griffin T. Bringing change-of-shift report to the bedside: a patient- and family-centered approach. Journal of Perinatal Neonatal Nursing, 2010 Oct-Dec;24(4):348-53 
Hewison, A., \& Stanton, A. (2003). From conflict to collaboration? Contrasts and convergence in the development of nursing and management theory (2). Journal of Nursing Management, 11(1), 15-24.

Institute for Patient and Family Centered Care (2008) Advancing the Practice of Patient and Family Centered Care: How to Get Started. Retrieved from http://www.ipfcc.org/pdf/getting_started.pdf

Jeffs, L., Beswick, S., Acott, A., Simpson, E., Cardoso, R., Campbell, H., \& Irwin, T. (2014). Patients' views on bedside nursing handover: Creating a space to connect. Journal of Nursing Care Quality, 29(2), 149-154. doi:10.1097/NCQ.0000000000000035

Johnson, M., \& Cowin, L. S. (2013). Nurses discuss bedside handover and using written handover sheets. Journal of Nursing Management, 21(1), 121-129.

Joint Commission. (2008). 2008 National Patient Goals PowerPoint Presentation. Retrieved from https://www.jointcommission.org/npsg_presentation/

Joint Commission Center for Transforming Healthcare. (2015). TST for hand-off communications. Retrieved from http://www.centerfortransforminghealthcare.org/tst_hoc.aspx

Kelly, M. (2005). Change from an office-based to a walk-around handover system. Nursing Times, 101(10), 34.

Kerr, M. P. (2002). A qualitative study of shift handover practice and function from a socio-technical perspective. Journal of Advanced Nursing, 37(2), 125-134.

Kerr, D., Lui, S., McKinlay, L., Fuller, C. (2011). Examination of current handover practice: Evidence to support changing the ritual. International Journal of Nursing 
Practice, 17, 342-350. doi:10.1111/j.1440-172X.2011.01947.x

Kravitz, R. L., \& Melnikow, J. (2001). Engaging patients in medical decision making. BMJ, 323(7313), 584-585.

Lu, S., Kerr, D., \& McKinlay, L. (2014). Bedside nursing handover: Patients' opinions. International Journal of Nursing Practice, 20(5), 451-459.

Manias, E., \& Street, A. (2000). The handover: Uncovering the hidden practices of nurses. Intensive and Critical Care Nursing, 16(6), 373-383.

Maxson, P. M., Derby, K. M., Wrobleski, D. M., \& Foss, D. M. (2012). Bedside nurseto-nurse handoff promotes patient safety. Medsurg Nursing, 21(3), 140.

McMurray, A., Chaboyer, W., Wallis, M., \& Fetherston, C. (2010). Implementing bedside handover: strategies for change management. Journal of Clinical Nursing, 19(17-18), 2580-2589.

Pothier, D., Monteiro, P., Mooktiar, M., \& Shaw, A. (2005). Pilot study to show the loss of important data in nursing handover. British Journal of Nursing, 14(20), 10901093.

Radtke, K. (2013). Improving patient satisfaction with nursing communication using bedside shift report. Clinical Nurse Specialist, 27(1), 19-25.

Robinson, L. (2009). A summary of diffusion of innovations. (graph). Available at http://www.enablingchange.com.au/Summary_Diffusion_Theory.pdf.

Rogers, E. M. (2003). Diffusion of innovations. (5ed.). Free Press: New York, NY.

Rogers, M. E. (1966). Doctoral education in nursing. Nursing forum 5(2) 75-82. doi: 10.1111/j.1744-6198.1966.tb00336.x 
Sand-Jecklin, K., \& Sherman, J. (2013). Incorporating bedside report into nursing handoff: evaluation of change in practice. Journal of Nursing Care Quality, 28(2), 186-194.

Scbifalacqua M, Coste! Jo C, Denman W (2009) Roadmap for planned change, part 1: change leadership and project management. Nurse Leader. 7, 2, 26-29.

Steis, M. R., Shaughnessy, M., \& Gordon, S. M. (2012). Delirium: a very common problem you may not recognize. Journal of Psychosocial Nursing and Mental Health Services, 50(7), 17-20.

Street, M., Eustace, P., Livingston, P. M., Craike, M. J., Kent, B., \& Patterson, D. (2011). Communication at the bedside to enhance patient care: a survey of nurses' experience and perspective of handover. International Journal of Nursing Practice, 17(2), 133-140. doi:10.1111/j.1440-172X.2011.01918.x

Studer, Q. (2003). Hardwiring excellence: Purpose Worthwhile Work Making a Difference. Fire Starter Pub, 2004

Taylor, J. S. (2015). Improving patient safety and satisfaction with standardized bedside handoff and walking rounds. Clinical journal of oncology nursing, 19(4), 414416.

Tobiano G, Chaboyer W, McMurray A. Family members' perceptions of the nursing bedside handover. Journal of Clinical Nursing. 2013;22(1-2):192-200

Wakefield, D. S., Ragan, R., Brandt, J., \& Tregnago, M. (2012). Making the transition to nursing bedside shift reports. Joint Commission Journal on Quality and Patient Safety, 38(6), 243-253. 
Welsh, C. A., Flanagan, M. E., \& Ebright, P. (2010). Barriers and facilitators to nursing handoffs: Recommendations for redesign. Nursing Outlook, 58(3), 148-154. doi:10.1016/j.outlook.2009.10.005

Wildner J \& Ferri P (2012). Patient participation in change-of-shift procedures: the implementation of the bedside handover for the improvement of nursing quality in an Italian hospice. Journal of Hospice and Palliative Nursing 14, 216-224. 


\section{Appendix A}

\section{Perceptions of Bedside Reporting - Nurses Survey}

Please circle the number that corresponds best with your answer

(Strongly Disagree-Disagree-Neutral-Agree-Strongly agree)

$\begin{array}{lllll}1 & 2 & 3 & 4 & 5\end{array}$

1. Bedside Report is an effective means of communication (Strongly Disagree-Disagree-Neutral-Agree-Strongly agree)

$\begin{array}{lllll}1 & 2 & 3 & 4 & 5\end{array}$

2. Bedside Report helps assure accountability between peers in effectively communicating patient information (Strongly Disagree-Disagree-Neutral-Agree-Strongly agree)
1
2
3
4
5

3. Bedside report gives opportunities for mentoring new staff

(Strongly Disagree-Disagree-Neutral-Agree-Strongly agree)

$\begin{array}{lllll}1 & 2 & 3 & 4 & 5\end{array}$

4. Bedside Report promotes patient involvement in care

(Strongly Disagree-Disagree-Neutral-Agree-Strongly agree)

$\begin{array}{llllll}1 & 2 & 3 & 4 & 5\end{array}$


5. Bedside Report improves patient safety

(Strongly Disagree-Disagree-Neutral-Agree-Strongly agree)

$\begin{array}{lllll}1 & 2 & 3 & 4 & 5\end{array}$

6. Bedside report helps me feel better informed about my patients

(Strongly Disagree-Disagree-Neutral-Agree-Strongly agree)

$\begin{array}{lllll}1 & 2 & 3 & 4 & 5\end{array}$

7. Bedside Report is completed in a reasonable time

(Strongly Disagree-Disagree-Neutral-Agree-Strongly agree)

$\begin{array}{lllll}1 & 2 & 3 & 4 & 5\end{array}$

8. I practice bedside reporting regularly

(Strongly Disagree-Disagree-Neutral-Agree-Strongly agree)

$\begin{array}{lllll}1 & 2 & 3 & 4 & 5\end{array}$

9 Overall, I like face to face interaction with the patient during bedside reporting (Strongly Disagree-Disagree-Neutral-Agree-Strongly agree)

$\begin{array}{lllll}1 & 2 & 3 & 4 & 5\end{array}$

10. I feel as though privacy is an issue with bedside report

(Strongly Disagree-Disagree-Neutral-Agree-Strongly agree)

$\begin{array}{lllll}1 & 2 & 3 & 4 & 5\end{array}$

These questions help to provide some information about your perceptions of bedside reporting. Can you give any further information that would help to understand your perceptions of this reporting method? 


\section{Appendix B \\ Informational Letter}

I, Christine McGinn RN, BSN am a graduate student at Rhode Island College currently enrolled in the Acute Care Nurse Practitioner Program. I would like to ask you to take part in a quality improvement project I am conducting on the perceptions of bedside nursing report. The project will aim to look at nurses' perceptions on bedside reporting in the ICU. It will look at what nurses like and/or dislike about the current practice of bedside report. You are being asked to participate in this project because as nurses you are involved in transfer of patient information from shift to shift. Over the past few years, bedside reporting was implemented on the unit and you have been involved in this reporting approach.

You are being asked to complete a brief survey to obtain information about your perceptions of this reporting process. Participation is completely voluntary and the survey will take approximately 10 minutes or less to complete. Surveys will be available on the unit and once completed will be placed securely in a locked box. Surveys will be keep confidential and secured in the Principal Investigators office.

\section{$\underline{\text { Risks or Discomfort }}$}

This study involves no foreseeable serious risks. I ask that you try to answer all questions; however, if there are any items that make you uncomfortable or that you would prefer to skip, please leave the answer blank. Your responses are anonymous. If you have any questions about this questionnaire or the project itself, please do not hesitate to contact me at 401575-6389 or ask me when you see me on the unit. In addition, if you have any questions you may contact Professor Debbie Servello, the director of the acute care program at Dservello@ ric.edu. In addition, if you have any questions about your rights as a participant please feel free to contact the Lifespan Institutional Review Board at 401-444-5843. 
Thank you for your participation,

Christine McGinn BSN, RN

Masters of Science Nursing Student

Rhode Island College 